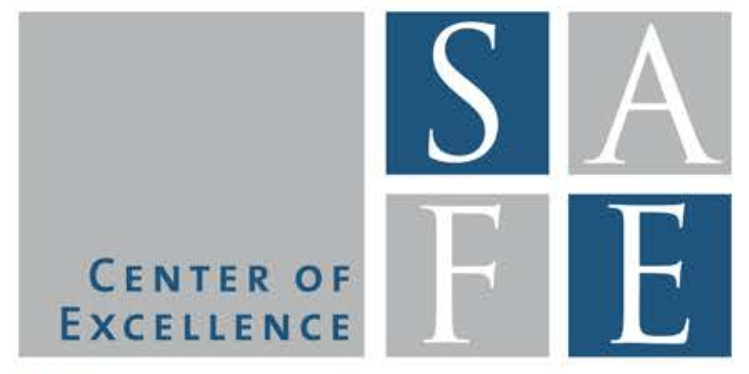

WORKING PAPER SERIES

Michael Kosfeld - Ulrich Schüwer

\title{
Add-on Pricing in Retail Financial Markets and the Fallacies of Consumer Education
}

SAFE Working Paper Series No. 47

Center of Excellence SAFE Sustainable Architecture for Finance in Europe A cooperation of the Center for Financial Studies and Goethe University Frankfurt 


\section{Non-Technical Summary}

Empirical evidence from retail financial markets shows that some consumers are naive about the full costs of the products they purchase. For example, they may not consider the costs of expensive overdrafts or high fees of investment products when they open a bank account. Retail banks - and more generally firms operating in markets with naive consumers - are likely to exploit this. As shown by previous research, the equilibrium pricing strategy of firms in a situation with sufficiently many naive consumers is to compete purely on the price of a base good (bank account) and to shroud information about prices of add-ons (overdrafts, investment products). While the base good is priced below marginal costs, the price of the add-on is above marginal costs. The consequences for consumers are twofold: First, sophisticated consumers who rationally expect that addons are overpriced will search for substitution possibilities, leading to smaller firm revenues and inefficiencies if substitution costs exceed firms' costs of production. Second, naive consumers who buy the add-on at the high price subsidize the low-priced base good and thereby also sophisticated consumers, which raises consumer protection concerns. The question is if and how a regulator may intervene to increase economic welfare and protect consumers in their decision making.

This paper examines the effectiveness of consumer education, which is a simple and popular form of regulatory intervention, to mitigate adverse effects for naive consumers. Intuition suggests that such initiatives - if effective - will have only positive effects on consumer protection and welfare, and may eventually lead to efficient market outcomes if only the educational boost is strong enough to make many naive consumers sophisticated. In contrast, our results show that this simple intuition is wrong. Due to firms' strategic responses welfare consequences of consumer education are more intricate and consumer education may actually cause unintended damages for consumers.

Allowing for different information and pricing strategies, our first key result shows that education is unlikely to push firms to disclose prices towards all consumers, which would be socially efficient. Instead, price discrimination emerges as a new equilibrium. This is what we view as the first fallacy of consumer education in retail financial markets: It is less relevant how consumer costs and welfare change when firms are pushed into a prices equilibrium where firms disclose prices towards all consumers (since this is unlikely to happen), but how these outcomes change in a price equilibrium where firms price discriminate between sophisticated and naive consumers.

The second key result of our model, and additional fallacy of consumer education, is that in contrast to common intuition, education which is good for the single educated consumer may be bad for consumers who stay naive and even for the group of consumers as a whole. Due to a strategic feedback on prices, educating some consumers may entail hidden costs for all other consumers, leading to increased prices and a reduction in overall welfare. 
Finally, we show that consumer education without knowing whether firms are able to engage in price discrimination or not yields effects that can go in any direction. Wellintentioned intervention may thus be harmful and a regulator's courses of action are again plagued with pitfalls.

As a general message our analysis suggests that regulators should act with caution when relying on consumer education to solve the problems of consumer protection and socially inefficient information and pricing strategies of firms. As our results show, consumer education is no panacea. 


\title{
Add-on Pricing in Retail Financial Markets and the Fallacies of Consumer Education
}

\author{
Michael Kosfeld and Ulrich Schüwer*
}

February 2014

\begin{abstract}
This paper explores consequences of consumer education on prices and welfare in retail financial markets when some consumers are naive about shrouded add-on prices and firms try to exploit it. Allowing for different information and pricing strategies we show that education is unlikely to push firms to disclose prices towards all consumers, which would be socially efficient. Instead, price discrimination emerges as a new equilibrium. Further, due to a feedback on prices, education that is good for consumers who become sophisticated may be bad for consumers who stay naive and even for the group of all consumers as a whole.
\end{abstract}

Keywords: Consumer education, financial literacy, bounded rationality, competition, regulation.

JEL Classification: D40, D80, L50

\footnotetext{
*Goethe University Frankfurt, kosfeld@econ.uni-frankfurt.de, schuewer@finance.uni-frankfurt.de. We would like to thank Johan Almenberg, Mark Armstrong, Roland Benabou, Patrick Rey, Reinhard H. Schmidt and seminar participants at the 2010 AEA meeting, Atlanta, the 2010 Econometric Society World Congress, Shanghai, the 2010 EARIE meeting, Istanbul, and the 2010 Verein für Socialpolitik meeting, Kiel, for helpful comments. A previous version of this paper was distributed as CEPR Discussion Paper No. DP8636 and IZA Discussion Paper No. 6061 under the title "Add-on Pricing, Naive Consumers, and the Hidden Welfare Costs of Education".
} 


\section{Introduction}

"Personal banking, like lunch, is not free. ... Yet the myth that banks are offering retail customers something for nothing persists to a degree that would be puzzling even if bankers were seen as national treasures. Andrew Bailey, [UK] banking regulation supremo, is the latest figure to set out the damage done by a business model in which the core product is a loss leader, bringing opacity and distortion in its wake. ... [To end this], banks would have to resist the temptation to slap charges on current accounts while continuing with the hefty fees and charges elsewhere that subsidise those accounts at the moment."

Financial Times, Nov. 24, 2011

If consumers are naive, firms are likely to exploit this. This is especially relevant in retail financial markets where banks intensely compete for customers to open a bank account at their branch, and then have strong market power to provide expensive overdrafts or to sell high-priced investment products to naive customers. ${ }^{1}$ Recent research finds that retail investors pay, on average, an 8 percent premium for popular structured equity products relative to the fair market value of these securities (Henderson and Pearson, 2011). Certainly, not all consumers are naive, but some are sophisticated and rationally expect that add-ons such as overdrafts and investment products are overpriced. These consumers typically search for substitution possibilities, e.g., they obtain credit from other sources to avoid overdraft fees or build their own diversified stock portfolio to avoid expensive investment funds. As shown by Gabaix and Laibson (2006), the equilibrium pricing strategy of firms in such a situation with sufficiently many naive consumers is to compete purely on the price of the base good (bank account) and to shroud information about the price of the addon (overdrafts, investment products). While the base good is priced below marginal costs the price of the add-on is above marginal costs.

The consequences for consumers are twofold: First, as described above, sophisticated consumers who rationally expect that add-ons are overpriced will search for substitution possibilities, leading to smaller firm revenues and inefficiencies if substitution costs exceed firms' costs of production. Second, naive consumers who buy the

\footnotetext{
${ }^{1}$ Other well-known examples are consumers who buy a printer without being aware of the costs of new printer cartridges (e.g., Hall, 1997), or travelers who book a hotel room without considering extra costs of parking or a minibar.
} 
add-on at the high price subsidize the low-priced base good and thereby also sophisticated consumers, which raises consumer protection concerns. The question is if and how a regulator may intervene to increase economic welfare and protect consumers in their decision making.

This paper examines the effectiveness of consumer education, which is a simple and popular form of regulatory intervention, to mitigate adverse effects for naive consumers. The issue of financial literacy has received large public attention in the light of the recent financial crisis. Several countries and organizations, including the OECD, US, EU, and UK have launched a number of financial education initiatives recently. ${ }^{2}$ Intuition suggests that such initiatives - if effective - will have only positive effects on consumer protection and welfare, and may eventually lead to efficient market outcomes if only the educational boost is strong enough to make many naive consumers sophisticated. In contrast, our results show that this simple intuition is wrong. Due to firms' strategic responses welfare consequences of consumer education are more intricate and consumer education may actually cause unintended damages for consumers.

We start our analysis by investigating firms' optimal information and pricing strategy when the population of consumers is composed of naive and sophisticated types. Firms can choose between: (i) high shrouded add-on prices for all consumers, (ii) low unshrouded add-on prices for all consumers, or (iii) high shrouded add-on prices for naive consumers and low unshrouded add-on prices for sophisticated consumers. The third strategy represents a particular form of third-degree price discrimination and is a new and important extension of the model of Gabaix and Laibson (2006) which only considers uniform pricing strategies, as reflected in strategies (i) and (ii) above. The idea is that firms have information about consumers that correlates with their degree of sophistication in making decisions. For example, consumers with a degree in finance are likely to make more sophisticated and better informed investment deci-

\footnotetext{
${ }^{2}$ According to OECD recommendations, "financial education is necessary to ensure sufficient levels of investor and consumer protection as well as the smooth functioning, not only of financial markets, but also of the economy." (OECD, 2009, p. 3). Similarly, Ben Bernanke, chairman of the Federal Reserve, recently stated that "among the lessons of the recent financial crisis is the need for virtually everyone - both young and old - to acquire a basic knowledge of finance and economics." (Bernanke, 2013).
} 
sions than consumers who have no such educational background. Banks may use this information to classify consumers as either naive or sophisticated and fine-tune their pricing strategy accordingly. However, the classification of consumers is unlikely to be perfect and we therefore allow for the possibility that firms may also erroneously classify a naive consumer as sophisticated or vice versa. We then analyze the effects of consumer education, i.e., increases in the share of sophisticated consumers, on firms information and pricing strategy and resulting consequence for consumer costs and welfare.

Our first result shows that price discrimination is sustained as a symmetric competitive equilibrium if firms can classify consumers relatively well and the fraction of naive consumers is neither very small nor very large. Otherwise, firms unshroud prices if the fraction of naive consumers is small and shroud the add-on price if the fraction of naive consumers is large. This result has an important consequence. In particular, as price discrimination becomes a new equilibrium, fully unshrouded prices, which would be the socially most desirable outcome, are even less likely to be observed even though markets are competitive and consumer education is effective. This is what we view as the first fallacy of consumer education in retail financial markets: It is in fact less relevant how consumer costs and welfare change when firms are pushed into an unshrouded prices equilibrium (since this is unlikely to happen), but how these outcomes change when consumers become more sophisticated within a price discrimination equilibrium.

The second key result of our model, and additional fallacy of consumer education, is that in contrast to common intuition, education which is good for the single educated consumer may be bad for consumers who stay naive and even for the group of consumers as a whole. Due to a strategic feedback on prices, educating some consumers may entail hidden costs for all other consumers, leading to increased prices and a reduction in overall welfare. Such negative effects, which in our model come in the form of substitution costs for sophisticated consumers, may be substantial. For example, sophisticated consumers who want to avoid overpriced structured equity products have to construct their own investment products using equities and 
derivatives, which generates high effort, information and search costs. ${ }^{3}$

Finally, we show that consumer education without knowing whether firms are able to engage in price discrimination or not yields effects that can go in any direction. Well-intentioned intervention may thus be harmful and a regulator's courses of action is again plagued with pitfalls. Overall, our analysis suggests that regulators are advised to carefully examine consumer and firm behavior before implementing the seemingly harmless intervention of consumer education.

Our study contributes to two main fields in the literature dealing with naive consumers in retail financial markets: information and pricing strategies of firms, and consumer education. Carlin (2009) argues that firms may add complexity to their price structures in order to prevent that consumers become informed and purchase the product at a lower price. Carlin and Manso (2011) study the interaction between obfuscation and investor sophistication, and find that investor education may increase obfuscation by firms, leading to more disorientation of investors and lower welfare. In practice, firms may use such obfuscation strategies as well as price discrimination strategies, which is the focus of our study.

Several empirical studies show that the effect of financial education on consumers' decisions is rather small. Choi et al. (2010), for example, find in an investment experiment with high monetary incentives that more than 80 percent of the participants fail to take into account substantial fees of investment products even when these fees are made transparent and salient. Other studies show that financial counseling or mandatory disclosure do little to improve the decisions of consumers in the mortgage market (Agarwal et al., 2009; Lacko and Pappalardo, 2010). Beshears et al. (2011) provide similar experimental evidence regarding investments in overpriced mutual

\footnotetext{
${ }^{3}$ Besides the already mentioned $8 \%$ retail premium for structured equity products (Henderson and Pearson, 2011), another example are high-priced investment funds, which often have fees between $1 \%$ and $2 \%$ per year. Low-priced alternatives, such as exchange-traded funds (ETFs) which often have annual fees as low as $0.1 \%$, were not available in the past. In Germany, for example, this has changed recently, potentially because sophisticated consumers otherwise substitute away. The largest German bank, Deutsche Bank, offers ETFs under the name $d b x$-trackers since 2007. The German savings banks offer ETFs under the name DEKA since 2008. However, based on anecdotal evidence, these banks almost never actively advertise for ETFs or suggest ETFs to their retail clients. Notably, Citibank Deutschland (now called Targobank and part of Credit Mutuel Group) until 2008 even did not allow customers to buy ETFs from external providers into their securities account, officially because of "technical difficulties".
} 
funds. Bhattacharya et al. (2012) document that only few retail investors are interested in free and independent investment advice, and if they obtain it, hardly follow the advice. ${ }^{4}$ We contribute to this literature by identifying important effects of consumer education on consumer prices and welfare exactly in those situations when educational effects are expected to be limited.

Finally, our study is also related to recent papers pointing to possible negative effects of transparency. For example, research shows that shrouded prices may be good for welfare if they increase consumption (Glaeser and Ujhelyi, 2010; De Meza and Reyniers, 2012) or allow firms to better price discriminate between low-demand and high-demand consumers (Grubb, 2012). Armstrong and Vickers (2012) study different policy options in relation to shrouded add-ons and also find that transparency may have negative effects on welfare. ${ }^{5}$

The paper is organized as follows. Section 2 presents the main model. Section 3 analyzes market equilibria. Section 4 contains the main results regarding effects of price discrimination on consumer costs and welfare. Section 5 then introduces consumer education and shows the respective effects. Finally, Section 6 concludes. The Appendix includes an overview on prices, consumer costs and welfare for the different prices equilibria (Section A1) and all proofs (Section A2).

\section{Model}

Our baseline model follows the one of Gabaix and Laibson (2006) (henceforth denoted as GL). There is finite number of firms offering a homogeneous base good and an add-on, which are both produced at zero marginal cost. In contrast to unavoidable surcharges, which is not considered in the model, the add-on is always avoidable for informed consumers. As an example further developed below, suppose that banks offer bank accounts as a base good and different types of investment funds as an

\footnotetext{
${ }^{4}$ See also De Meza et al. (2008) and Hastings et al. (2013) for a more general literature review on financial education.

${ }^{5}$ These papers belong to a growing literature that studies in more general the effects of bounded rationality in industrial organization. See Ellison (2006) and Spiegler (2011) for an overview of the field.
} 
add-on.

The mass of consumers is normalized to 1. Consumers are of two types: A fraction $\alpha \in(0,1)$ of consumers are naive (myopic, in the language of GL), they only take the price of the base good into consideration when deciding to purchase at the firm. The remaining fraction $1-\alpha$ are sophisticated and consider both the price of the base good and the price of the add-on. In case firms do not advertise the add-on, sophisticated consumers form Bayesian posteriors about the add-on price.

Let $p$ denote the price of the base good and $\hat{p}$ the price of the add-on. We focus on symmetric price equilibria throughout the paper and hence omit firm-subscripts whenever doing so causes no confusion. As in GL, firms can decide to shroud or unshroud add-on prices when consumers make a buying decision about the base good. Both activities are free. Shrouding means that firms suppress information about the price of the add-on. Unshrouding means that firms advertise the price of the addon broadly. If a firm unshrouds, all sophisticated consumers as well as a fraction $\lambda_{F} \in[0,1)$ of naive consumers become informed about the price of the add-on and take it into account when purchasing the good. The latter group of informed naive consumers is the result of the educational effect of a firm's unshrouding activity. These consumers are initially naive but behave just like sophisticated consumers once a firm unshrouds. The remaining fraction $1-\lambda_{F}$ of naive consumers do not take the add-on price into consideration even when firms unshroud. This group of uninformed naive consumers is either not receptive or not able to use the relevant information.

Consumers have a maximum willingness to pay for the add-on $\bar{p}$, which sets an upper bound for the price $\hat{p}$, i.e., $\hat{p} \leq \bar{p}$. In addition, consumers who are informed about or expect high add-on prices, can avoid the add-on by substituting away at cost $e<\bar{p}$. Hence, firms can charge a maximum add-on price $\bar{p}$ from uninformed naive consumers and $e$ from sophisticated and informed naive consumers.

Following GL we analyze price competition by modeling the demand at firm $i$ as the probability $D\left(x_{i}\right)$ that a consumer purchases a product at that firm. The probability depends on $x_{i}$, which denotes the anticipated net surplus from purchasing at firm $i$ minus the anticipated net surplus from purchasing at the best alternative 
firm. ${ }^{6}$

As firms sell homogenous goods, the anticipated net surplus of uninformed naive consumers who do not take the add-on price into consideration equals

$$
x_{i}=-p_{i}+p^{*},
$$

where $p_{i}$ and $p^{*}$ denote the price of the base good at firm $i$ and the price of the base good at the best alternative firm, respectively. For a sophisticated (and an informed naive) consumer, who takes both the price of the base good and the price of the add-on into account, anticipated net surplus equals

$$
x_{i}=-p_{i}-\min \left\{E \hat{p}_{i}, e\right\}+p^{*}+\min \left\{E \hat{p}^{*}, e\right\},
$$

where $E \hat{p}_{i}$ and $E \hat{p}^{*}$ represent the expected add-on price at firm $i$ and the expected add-on price at the best alternative firm, respectively. If information is unshrouded, $E \hat{p}_{i}=\hat{p}_{i}$ and $E \hat{p}^{*}=\hat{p}^{*}$.

A key innovation in our model is that, in addition to fully (un)shrouding add-on prices, firms can make different price offers to consumers who they classify as naive or sophisticated. This strategy results in partial (un)shrouding and is similar to a particular form of third-degree price discrimination. ${ }^{7}$ More precisely, we assume that firms can use available information about consumers, such as education or employment, to classify consumers. For instance, banks typically know whether their costumers have an academic background, work at a bank or have a degree in finance or business. They can then advertise the price of their bank account broadly to all costumers and withhold special information about low-priced investment funds, such as exchange-traded funds (ETFs), to those, e.g., with a degree in finance. All remaining costumers are not made aware of these funds but are offered, once they have opened a bank account,

\footnotetext{
${ }^{6}$ Formally, the demand function can be derived from a random-utility model, where individual $a$ consuming product $i$ has utility $U_{a i}=v-p_{i}+\varepsilon_{a i}$, with $v$ and $p_{i}$ denoting the quality and the price of the product, respectively, and $\varepsilon_{a i}$ denoting a random idiosyncratic preference component that is i.i.d. across consumers and products. Cf. GL, p. 532-533 and Anderson et al. (1992) for details.

${ }^{7}$ Other extensions of GL include the consideration of price floors (Miao, 2010), price caps (Ko and Williams, 2013) and the differentiation of "socially valuable" and "socially wasteful" products (Heidhues et al., 2012).
} 
only actively managed investment funds with high annual fees.

Thus, firms on the one hand unshroud add-on prices towards consumers whom they classify as sophisticated because they assume that these consumers otherwise form Bayesian posteriors about the add-on price and substitute away. The advertised add-on price for these consumers, $\hat{p}_{S}$, cannot exceed $e$, the substitution costs of sophisticated consumers. On the other hand, firms shroud information towards consumers classified as naive. The add-on price for these consumers, $\hat{p}_{N}$, is at most $\bar{p}$, the reservation price of uninformed naive consumers. Furthermore, firms advertise the base good to all consumers for a price $p .{ }^{8}$

We allow for the possibility that firms make mistakes when classifying consumers. With probability $1-\beta$, firms erroneously classify a sophisticated consumer as naive. Further, with probability $1-\gamma$, firms erroneously classify a naive consumer as sophisticated. Intuitively, $\beta, \gamma \in[0,1]$ model the accuracy of firms' consumer classification. The larger these parameters, the better firms can identify a consumer's true type. As long as $\beta$ and $\gamma$ are strictly below 1, misclassification implies that firms unshroud the low add-on price $\hat{p}_{S}$ towards a non-zero fraction of naive consumers while a non-zero fraction of sophisticated consumers will not receive the low-price offer. In equilibrium, the latter group will therefore substitute away because they expect high prices while the former group will earn a rent. ${ }^{9}$

Considering again our example, we thus assume that a fraction $1-\gamma$ of naive consumers have a degree in finance and are hence erroneously classified as sophisticated. These naive consumers then profit from the misclassification because they are offered the ETF with low annual fees, although they would have bought the more expensive, actively managed fund, as well. Further, a fraction $1-\beta$ of sophisticated

\footnotetext{
${ }^{8}$ In principle, firms could also offer the base good to sophisticated and naive consumers at different prices $p_{S}$ and $p_{N}$, respectively. However, we assume that sophisticated consumers can, costlessly or at relatively low costs, observe and take advantage of the base good price $p_{N}$ offered to naive consumers. For example, they find out that a bank advertises bank accounts at a low (subsidized) price to naive consumers, and they then go to this bank and open a bank account at the low price. This implies that firms do not offer the base good at different prices because a low price for naive consumers also attracts sophisticated consumers (who then substitute away on the expensive add-on).

${ }^{9}$ We show below that a necessary condition for price discrimination to be an equilibrium is that $\beta>1-\gamma$.
} 
consumers do not have a finance degree and are therefore erroneously classified as naive. These consumers build their own diversified portfolio (i.e., substitute away) at cost $e$, because they do not get any information about the low-priced add-on and expect that the bank offers an actively managed fund with high annual fees. ${ }^{10}$

The timing of decisions in our model is as follows:

\section{Period 1}

- Firms choose their information and pricing strategy.

* In case of shrouding, firms suppress information about the add-on. They pick a price for the base good, $p$, and a price for the add-on, $\hat{p}$.

* In case of unshrouding, firms advertise the add-on price towards all consumers. Unshrouding makes sophisticated consumers and a fraction $\lambda_{F}$ of naive consumers aware of the add-on price. Firms also pick prices $p$ and $\hat{p}$.

* In case of price discrimination, firms shroud add-on prices towards consumers classified as naive and unshroud add-on prices towards consumers classified as sophisticated. Firms pick a price for the base good, $p$, and prices for the add-on, $\hat{p}_{N}$ and $\hat{p}_{S}$, for consumers classified as naive and sophisticated, respectively.

\section{Period 2}

- Informed consumers (sophisticated and informed naive) always take the price of the add-on into consideration. Informed consumers who do not receive any information about the add-on (because firms shroud or they are erroneously classified as naive), form Bayesian posteriors about the add-on price.

- Uninformed naive consumers do not consider the add-on for their buying decision.

- Consumers choose a firm.

\footnotetext{
${ }^{10}$ If some or all misclassified sophisticated consumers can observe that other (correctly classified) sophisticated consumers are offered a low-priced add-on and then buy it for $e$ instead of substituting away at $\operatorname{costs} e$, this can be interpreted as a de facto higher classification accuracy $\beta$.
} 
- Informed consumers can decide to substitute away at cost $e .^{11}$

\section{Period 3}

- All consumers buy the base good.

- Consumers observe the add-on price (if they have not done so already).

- Uninformed consumers buy the add-on if the price is at most their reservation price $\bar{p}$.

- Informed consumers buy the add-on if they have not already substituted away in period 2 .

\section{Price Equilibria}

GL show that there exist two symmetric equilibria in their model: a shrouded prices and an unshrouded prices equilibrium. The existence of these equilibria depends on the share of naive consumers in the population, the substitution costs and the upper bound for the add-on price. If the share of naive consumers is relatively large, i.e. $\alpha>\frac{e}{\bar{p}}$, a shrouded prices equilibrium exists. If there are relatively few naive consumers, i.e. $\alpha<\frac{e}{\bar{p}}$, an unshrouded prices equilibrium exists.

Our first result extends the GL-result by showing that firms' possibility to classify consumers as naive or sophisticated changes both the thresholds above and the set of equilibria, leading to a new price discrimination equilibrium if the share of naive consumers is intermediate.

Proposition 1 (Price Equilibria). Let

$$
\alpha^{\dagger}=\min \left(\frac{e}{\bar{p}}, \frac{e(1-\beta)}{e(1-\beta)+(\bar{p}-e) \gamma}\right)
$$

and

$$
\alpha^{\ddagger}=\max \left(\frac{e}{\bar{p}}, \frac{e \beta}{e \beta+(\bar{p}-e)(1-\gamma)}\right) .
$$

\footnotetext{
${ }^{11}$ Like GL we assume that substitution costs occur prior to the purchase of the base good.
} 
If $\alpha<\alpha^{\dagger}$, there exists an equilibrium, in which firms unshroud the add-on price and set $\hat{p}=e$ (unshrouded prices equilibrium). If $\alpha^{\dagger}<\alpha<\alpha^{\ddagger}$, there exists an equilibrium, in which firms engage in price discrimination with $\hat{p}_{S}=e$ and $\hat{p}_{N}=\bar{p}$ (price discrimination equilibrium). If $\alpha^{\ddagger}<\alpha$, there exists an equilibrium, in which firms shroud the add-on price and set $\hat{p}=\bar{p}$ (shrouded prices equilibrium).

All proofs are in the Appendix.

Proposition 1 is illustrated in Figure 1. If the share of naive consumers is small $\left(\alpha<\alpha^{\dagger}\right)$, firms optimally sell the add-on to every consumer. As sophisticated consumers substitute away if they observe (or expect) add-on prices larger than $e$, firms set price $\hat{p}=e$ and unshroud. From the first-order condition $\left(p+\hat{p}=\frac{D(0)}{D^{\prime}(0)}=\mu\right)$ it follows that the price of the base good is equal to $\mu-e$ in the unshrouded prices equilibrium.

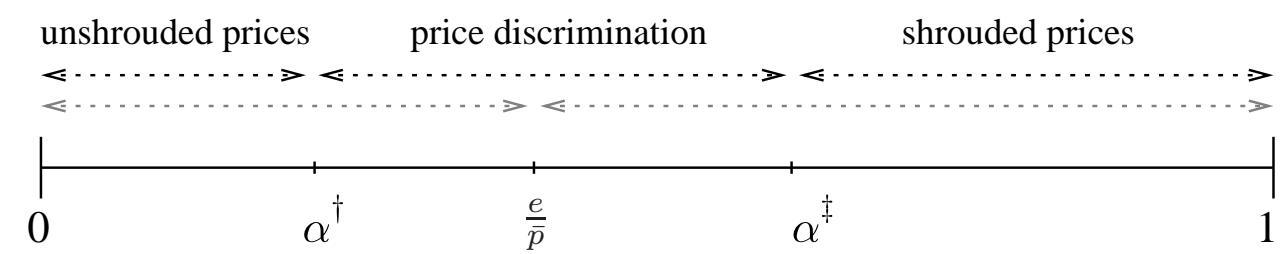

Note: For a situation where firms can classify consumers relatively well, the upper dashed lines illustrate that price discrimination is an equilibrium pricing strategy if the share of naive consumers $\alpha$ is intermediate. Without the possibility to use price discrimination, firms either choose unshrouded prices or shrouded prices depending on $\alpha$ (lower dashed lines).

Figure 1: Price Equilibria with (and without) Price Discrimination

If the share of naive consumers is intermediate $\left(\alpha^{\dagger}<\alpha<\alpha^{\ddagger}\right)$, price discrimination is an equilibrium strategy. A necessary condition is that $\alpha^{\dagger}<\alpha^{\ddagger}$, which holds if and only if $\beta>1-\gamma$, i.e., errors from misclassification are small. Firms choose the highest possible add-on price $\hat{p}_{N}=\bar{p}$ as a standard, which they shroud, and make special offers $\hat{p}_{S}=e$ to consumers who they classify as sophisticated. If $\beta<1$, some sophisticated consumers are misclassified and do not receive the special offer. These consumers see that firms shroud, conclude that $E \hat{p}=\bar{p}$ and hence substitute away. Firms accept this as the share of naive consumers is sufficiently large such that it pays to shroud the high add-on price. On the other hand, if $\gamma<1$, there are some naive consumers who buy the add-on at a price $\hat{p}_{S}=e$ that is strictly below 
their reservation price $\bar{p}$. Firms accept this as well, as the share of naive consumers is not large enough for it to pay to ignore sophisticated consumers and shroud the add-on completely. Note that price discrimination yields higher revenue for firms on the add-on. However, competition on the base-good market forces firms to pass this extra revenue to consumers in the form of lower base-good prices. ${ }^{12}$ In the price discrimination equilibrium, the price of the base good is therefore lower than in the unshrouded prices equilibrium. From the first-order condition we get that it is equal to $\mu-\alpha \gamma \bar{p}-e(\alpha(1-\gamma)+(1-\alpha) \beta) .{ }^{13}$

Finally, a shrouded prices equilibrium exists, if the share of naive consumers is large $\left(\alpha>\alpha^{\ddagger}\right)$. In this case, firms sell the add-on at the highest possible price $\hat{p}=\bar{p}$ to naive consumers only. Information is shrouded because unshrouding decreases the fraction of uninformed consumers. Sophisticated consumers observe that firms shroud, rationally expect that $E \hat{p}=\bar{p}$ and hence substitute away. Again, all extra revenue on the add-on is competed away in the base-good market, leading to a price for the base good equal to $\mu-\alpha \bar{p}$.

Note that a necessary condition for price discrimination to be an equilibrium is that the interval $\left[\alpha^{\dagger}, \alpha^{\ddagger}\right]$ exists, which is equivalent to $\beta>1-\gamma$. If this condition is not fulfilled, Proposition 1 is equivalent to the main result in GL, as the following corollary summarizes.

Corollary 1 (No Price Discrimination). Suppose that $\beta \leq 1-\gamma$. This implies that $a^{\dagger}=\alpha^{\ddagger}=\frac{e}{\bar{p}}$. There exist an unshrouded prices equilibrium if $\alpha<\frac{e}{\bar{p}}$ and a shrouded prices equilibrium if $\alpha>\frac{e}{\bar{p}}$.

Next, if errors are relatively small and in addition sophisticated consumers can be classified perfectly $(1-\gamma<\beta=1)$, price discrimination always dominates unshrouding. In consequence, the unshrouded prices equilibrium no longer exists.

Corollary 2 (No Unshrouding). Suppose that $1-\gamma<\beta=1$. This implies that $\alpha^{\dagger}=0$ and $\alpha^{\ddagger}=\frac{e}{e+(\bar{p}-e)(1-\gamma)}$. There exist a price discrimination equilibrium if $\alpha<\alpha^{\ddagger}$ and a shrouded prices equilibrium if $\alpha>\alpha^{\ddagger}$.

\footnotetext{
${ }^{12}$ Hence, firms' pricing strategies represent a particular form of loss-leader pricing. See Lal and Matutes (1994).

${ }^{13}$ See the Appendix for details.
} 
Similarly, if errors are small and uninformed naive consumers can be classified perfectly $(1-\beta<\gamma=1)$, price discrimination dominates shrouding. Thus, the shrouded prices equilibrium no longer exists.

Corollary 3 (No Shrouding). Suppose that $1-\beta<\gamma=1$. This implies that $\alpha^{\dagger}=$ $\frac{e(1-\beta)}{e(1-\beta)+(\bar{p}-e)}$ and $\alpha^{\ddagger}=1$. There only exist a unshrouded prices equilibrium if $\alpha<\alpha^{\dagger}$ and a price discrimination equilibrium if $\alpha>\alpha^{\dagger}$.

Together Corollary 2 and 3 imply that if both consumer types are classified perfectly $(\beta=\gamma=1)$, neither shrouding nor unshrouding can be an equilibrium, and only the price discrimination equilibrium remains. ${ }^{14}$

\section{Consumer Costs and Welfare}

An immediate question is, who benefits from firms' possibility to use price discrimination? In the following, we analyze in detail the impact of price discrimination on consumer costs and economic welfare. Our analysis follows an equilibrium approach, i.e., we compare equilibrium outcomes in case firms can use price discrimination to equilibrium outcomes if price discrimination is not possible. Note that if firms price-discriminate, total costs of consumption of ex-ante naive consumers depend on whether consumers become informed about add-ons or stay uninformed as firms partially unshroud. We interpret the fraction of naive consumers who become informed as the probability for an ex-ante naive consumer to become informed and thus calculate the expected costs of consumption of ex-ante naive consumers.

Our first result shows that sophisticated consumers always gain from price discrimination, whereas naive consumers may loose depending on what equilibrium is replaced.

\footnotetext{
${ }^{14}$ There exists a non-empty interval to the right of $\alpha^{\dagger}$, in which both the price discrimination and the unshrouded prices equilibrium co-exist. A similar interval exists to the right of $\alpha^{\ddagger}$, in which the price discrimination and the shrouded prices equilibrium co-exist. The size of these intervals depend on $\lambda_{F}$ (see the proof of Proposition 1 for details). Since the multiplicity of equilibria is not immediately relevant for the results in our model, we do not consider this issue any further in the following.
} 
Proposition 2 (Consumer Costs). Sophisticated consumers always gain from price discrimination, i.e., their costs of consumption are strictly lower than in a corresponding shrouded or unshrouded prices equilibrium $\left(\alpha^{\dagger}<\alpha<\alpha^{\ddagger}\right)$. Expected costs of exante naive consumers decrease relative to a shrouded prices equilibrium $\left(\frac{e}{\bar{p}}<\alpha<\alpha^{\ddagger}\right)$ but increase relative to an unshrouded prices equilibrium $\left(\alpha^{\dagger}<\alpha<\frac{e}{\bar{p}}\right)$. The reason is that correctly classified naive consumers face lower (higher) costs of consumption when firms price discriminate compared to an shrouded (unshrouded) prices equilibrium. Misclassified naive consumers always gain from price discrimination.

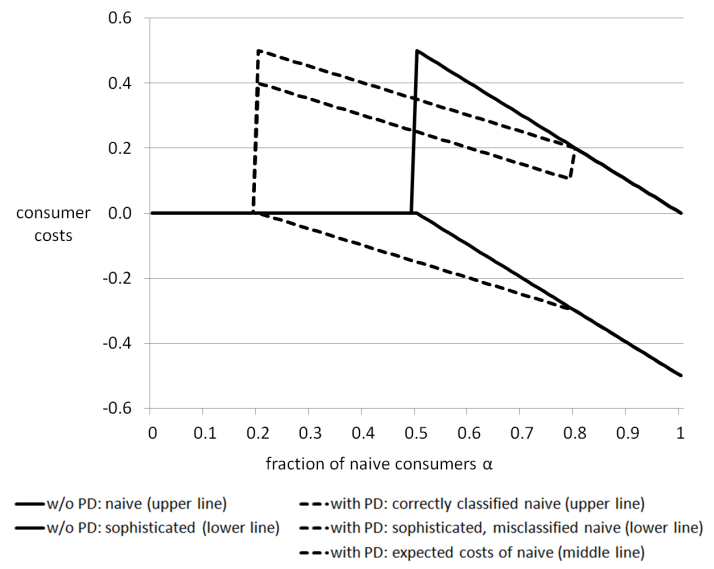

(a) Consumer Costs

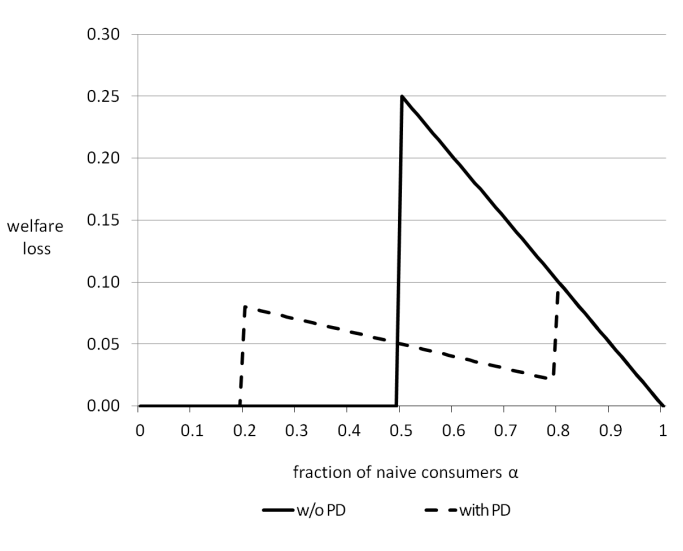

(b) Welfare Loss

Note: Parameters are $\bar{p}=1, e=0.5, \mu=0$ and $\beta \leq 1-\gamma$ without price discrimination (solid lines) or $\beta=\gamma=0.8$ with price discrimination (dashed lines). Resulting equilibrium thresholds are $\alpha^{\dagger}=\alpha^{\ddagger}=0.5$ without price discrimination or $\alpha^{\dagger}=0.2$ and $\alpha^{\ddagger}=0.8$ with price discrimination.

Figure 2: Consumer Costs and Welfare with (and without) Price Discrimination

Proposition 2 is illustrated in panel (a) of Figure 2, which shows equilibrium consumer costs for a particular combination of parameters. In this example, firms are always in an unshrouded prices equilibrium for $\alpha<\alpha^{\dagger}=0.2$ and in a shrouded prices equilibrium for $\alpha>\alpha^{\ddagger}=0.8$. Without price discrimination, these regions expand until they meet at $\alpha=e / \bar{p}=0.5$. In contrast, if price discrimination is possible and optimal, it replaces the other two equilibria for $0.2<\alpha<0.8$. The figure reveals that naive consumers who are classified correctly (upper dashed line) are the ones who potentially loose from price discrimination. They pay the high add-on price $\bar{p}$ whenever $\alpha>0.2$. For $0.2<\alpha<0.5$ this is much more than they would pay in an 
otherwise unshrouded prices equilibrium. However, for $0.5<\alpha<0.8$ they benefit, because the base good price is now lower compared to the otherwise shrouded prices equilibrium due to more add-on sales to sophisticated consumers. Note that the same holds also in expectation for ex-ante naive consumers (middle dashed line). Finally, sophisticated consumers as well as naive consumers who are misclassified by firms (lower dashed line) always gain from price discrimination.

The effects on consumer costs lead to the following effects on economic welfare. ${ }^{15}$

Proposition 3 (Economic Welfare). Price discrimination strictly increases economic welfare relative to a shrouded prices equilibrium $\left(\frac{e}{\bar{p}}<\alpha<\alpha^{\ddagger}\right)$ and weakly decreases economic welfare relative to an unshrouded prices equilibrium $\left(\alpha^{\dagger}<\alpha<\frac{e}{\bar{p}}\right)$.

In terms of economic welfare, price discrimination represents a clear improvement relative to a shrouded prices equilibrium, because less sophisticated consumers substitute away as they get informed about the low-priced add-on. The better firms can target sophisticated consumers, the lower is the fraction of consumers substituting away and thus the higher is economic welfare. If consumer classification is perfect $(\beta=1)$, the welfare loss is zero, just as in the unshrouded prices equilibrium. If $\beta<1$, however, price discrimination decreases welfare in the case where firms would unshroud prices otherwise.

Figure 2 (b) illustrates Proposition 3, showing that price discrimination (dashed line) decreases the loss in welfare relative to a shrouded prices equilibrium $(0.5<$ $\alpha<0.8$ ) but increases the loss in welfare relative to an unshrouded prices equilibrium $(0.2<\alpha<0.5)$.

Table 1 in the appendix summarizes the effects on prices, consumer costs, and welfare.

\footnotetext{
${ }^{15}$ Note that economic welfare is fully captured by consumer costs in our model, because firm equilibrium profit is constant. As firms produce at zero marginal cost, firm profit per consumer is determined by the average total price of the base good and the add-on. In equilibrium, this price is determined by the demand function $D$ and is equal to $\mu=\frac{D(0)}{D^{\prime}(0)}$ in any equilibrium.
} 


\section{The Effects of Consumer Education}

Suppose now that the regulator can educate a fraction $\lambda_{R} \in[0,1)$ of naive consumers before firms decide on their information and pricing strategy. We assume that such intervention increases the share of sophisticated consumers in the population prior to, and independent of, any potential educational effect of a firm's (partial) unshrouding strategy from $1-\alpha$ to $1-\left(1-\lambda_{R}\right) \alpha$. To abstract from implementation costs we assume that educating consumers is free.

There are two potential reasons for such an intervention. The first reason is that market outcomes are inefficient because some consumers - the sophisticated - exert costly effort to substitute add-ons that can costlessly be produced by firms. This inefficiency arises whenever firms shroud the add-on or price discriminate but do not reach all sophisticated consumers. The second reason for intervention is that some consumers - the naive - pay too much for the add-on and thus serve as a cash cow which subsidizes low base good prices for sophisticated consumers. Again, this may happen when firms either shroud the add-on or choose (imperfect) price discrimination.

\subsection{Price Equilibria}

Our first result shows that regulatory intervention shifts equilibrium thresholds as specified in Proposition 1 to the right.

Lemma 1 (Price Equilibria with Consumer Education). Suppose the regulator increases the share of sophisticated consumers by $\lambda_{R} \alpha$. Let $\alpha^{\S}=\frac{1}{1-\lambda_{R}} \alpha^{\dagger}$ and $\alpha^{\sharp}=$ $\frac{1}{1-\lambda_{R}} \alpha^{\ddagger}$. An unshrouded prices equilibrium exists if $\alpha<\alpha^{\S}$, a price discrimination equilibrium exists if $\alpha^{\S}<\alpha<\alpha^{\sharp}$, and a shrouded prices equilibrium exists if $\alpha^{\sharp}<\alpha$.

Figure 3 illustrates the effect of regulatory intervention on equilibrium thresholds and corresponding equilibrium intervals. As can be seen, both the area where firms unshroud prices and the area where firms price discriminate in equilibrium increases, whereas the area, in which firms shroud prices becomes smaller. The size of the right shift depends on $\lambda_{R}$. The more naive consumers are affected by consumer education 
the greater is the effect on firms' equilibrium behavior and corresponding market outcomes.

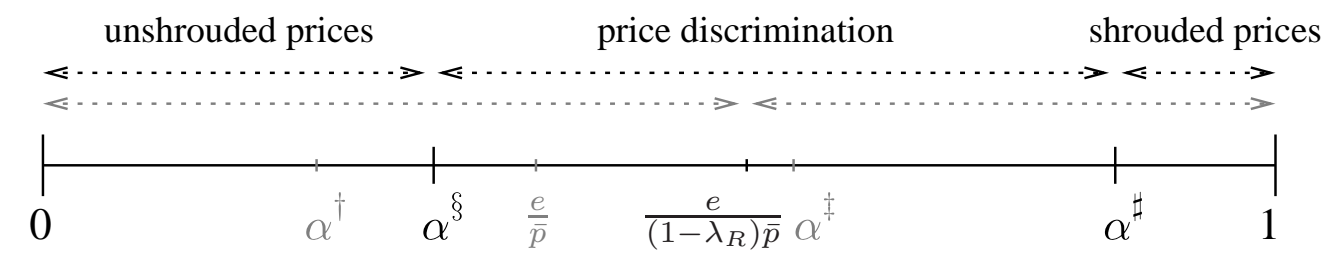

Note: The upper dashed lines illustrate the new equilibrium thresholds after consumer education in terms of ex-ante naive consumers $\alpha$. These new thresholds are higher than the thresholds before consumer education (lower dashed lines) because education makes a fraction of ex-ante naive consumers sophisticated.

Figure 3: Price Equilibria with (and without) Consumer Education

Note that the possibility of firms to react to a higher share of sophisticated consumers via price discrimination makes it more difficult for the regulator to achieve an unshrouded prices equilibrium. In particular, when firms are in a shrouded prices equilibrium before regulatory intervention, consumer education may lead to an unshrouded prices equilibrium if firms cannot engage in price discrimination and to a price discrimination equilibrium otherwise. This suggests that there are important interaction effects between consumer education and price discrimination. We will address these effects below.

\subsection{Consumer Costs and Welfare}

Obviously, intervention is unnecessary if firms are in an unshrouded prices equilibrium. In this case, no consumer substitutes away and all consumers pay the same prices. The main question is therefore, what effects does regulatory intervention have when firms are in a shrouded or in a price discrimination equilibrium. As the following proposition shows, increasing consumer sophistication generates both losses and gains for different types of consumers.

Proposition 4 (Effects of Consumer Education on Consumer Costs). Consumer education has zero effect on consumer costs if firms are in an unshrouded prices equilibrium before intervention $\left(\alpha<\alpha^{\dagger}\right)$. In all other cases, ex-ante naive consumers who 
are educated through the intervention gain, i.e., they have lower consumer costs than before. However, sophisticated consumers and in most cases also naive consumers who stay naive are on the losing side: their costs of consumption increase. ${ }^{16}$

Proposition 4 is illustrated in panel (a) of Figure 4, which considers the same combination of parameters as panel (a) of Figure 2. The solid lines show consumer costs before consumer education for sophisticated (lower solid line) and naive consumers (upper solid line) in an unshrouded prices equilibrium $(\alpha<0.2)$, a price discrimination equilibrium $(0.2<\alpha<0.8)$ and a shrouded prices equilibrium $(\alpha>0.8)$, respectively. ${ }^{17}$ The dashed lines show consumer costs after education with new equilibrium thresholds equal to $\alpha^{\S}=0.33$ and $\alpha^{\sharp}=1.33$. The upper dashed line shows the costs for consumers who are "immune" to education, i.e., who are naive ex ante and remain naive also if the regulator intervenes. The lower dashed line shows consumer costs for sophisticated consumers and for ex-ante naive consumers who are educated through the intervention. The middle dashed line shows expected costs of ex-ante naive consumers. Importantly, the effect of consumer education is given by the difference between the dashed and solid lines for the different types of consumers.

As Figure 4 (a) shows, consumer costs are unaffected for $\alpha<0.2$. If $0.2<$ $\alpha<0.33$, costs of naive consumers decrease independent of whether they are actually educated by the intervention or not, since firms unshroud prices in the new equilibrium anyway. For larger $\alpha$, the effect on costs depends on whether a naive consumer is educated or not. On the one hand, ex-ante naive consumers who are educated always have lower consumer costs after regulation (lower dashed line) than before (upper solid line). Ex-ante naive consumers who remain naive, on the other hand, have higher costs after regulation (upper dashed line) than before (upper solid line). Sophisticated consumers, however, lose for sure: they always face higher consumer costs after regulation (lower dashed line) than before (lower solid line). Thus, while the intervention decreases the costs of the target group - ex-ante naive consumers

\footnotetext{
${ }^{16}$ The only case in which naive consumers, who remain naive, can gain is if firms are pushed from a shrouded prices to a price discrimination equilibrium and the probability of being misclassified is sufficiently high. Formally, $\alpha^{\ddagger}<\alpha<\alpha^{\sharp}$ and $(1-\alpha) \bar{p}>\left(1-\left(1-\lambda_{R}\right) \alpha\right)(\gamma \bar{p}+e(1-\gamma)-e \beta)$. See the appendix for details.

${ }^{17}$ In case of price discrimination, consumer costs for naive consumers depend on whether they are classified correctly or misclassified. The Figure shows expected costs.
} 
who become educated — it simultaneously increases the costs of other consumers.

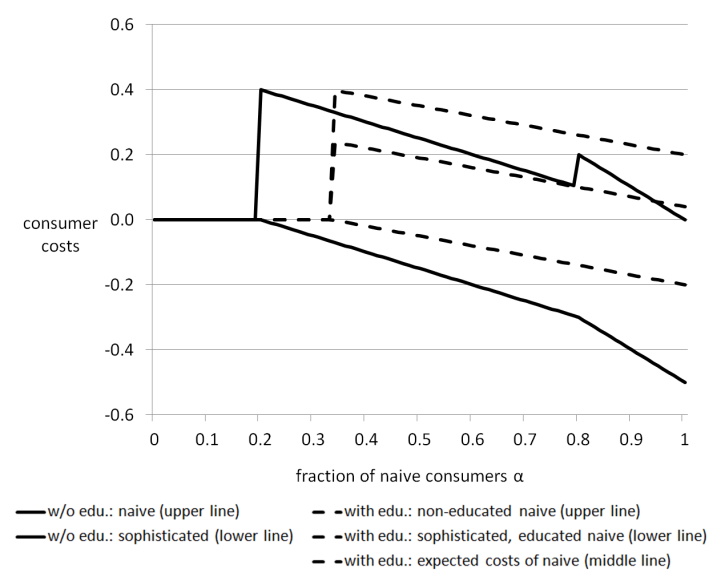

(a) Consumer Costs

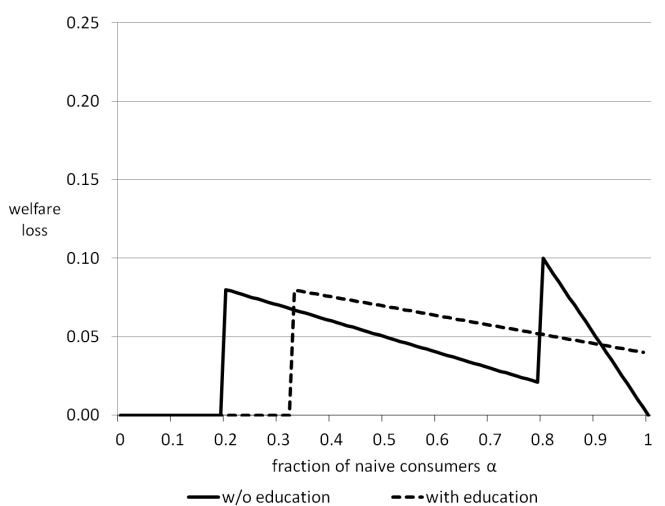

(b) Welfare Loss

Note: Parameters are $\bar{p}=1, e=0.5, \mu=0, \beta=\gamma=0.8$ and a potential educational effect $\lambda_{R}=0.4$. Resulting equilibrium thresholds are $\alpha^{\dagger}=0.2$ and $\alpha^{\ddagger}=0.8$ without consumer education (solid lines) or $\alpha^{\S}=1 / 3$ and $\alpha^{\sharp}=4 / 3$ with consumer education (dashed lines).

Figure 4: Consumer Costs and Welfare with (and without) Consumer Education

Note that consumer education can even lead to an increase in expected costs of ex-ante naive consumers alone. This happens in panel (a) of Figure 4 if $\alpha \geq 0.95$. For other combinations of parameters, this area can even be larger (e.g., $\alpha>0.7$ for $\bar{p}=1, e=0.3, \beta=\gamma=0.7, \mu=0$ and $\left.\lambda_{R}=0.3\right)$. In these cases, the benefit for the educated naive consumers is already offset by the damage to those who remain naive. Thus, even a regulator who focuses exclusively on the welfare of naive consumers and neglects any impact on the sophisticated should refrain from intervention in this case.

The previous proposition shows that increasing consumer sophistication causes both harm and good in terms of consumer costs. Whenever the former outweighs the latter, regulatory intervention leads to a negative effect on welfare as the following proposition summarizes.

Proposition 5 (Welfare Effects of Consumer Education). Consumer education has no effect on welfare if firms are in an unshrouded prices equilibrium before intervention $\left(\alpha<\alpha^{\dagger}\right)$. It has a clear positive effect on welfare only if firms are pushed into an unshrouded prices equilibrium after intervention $\left(\alpha^{\dagger}<\alpha<\alpha^{\S}\right)$. In all other cases, welfare effects can be negative. In particular, effects are always negative if a shrouded prices equilibrium $\left(\alpha^{\sharp}<\alpha\right)$ or a price discrimination equilibrium $\left(\alpha^{\S}<\alpha<\alpha^{\ddagger}\right)$ 
remains. Effects are ambiguous if firms are pushed from shrouded prices towards price discrimination $\left(\alpha^{\ddagger}<\alpha<\alpha^{\sharp}\right)$.

Panel (b) of Figure 4 illustrates how consumer education affects welfare, as stated in Proposition 5. The solid line shows the welfare loss before regulatory intervention in the respective price equilibria. The dashed line indicates the welfare loss in the new equilibrium situations after consumer education. The difference between the two lines is the net effect on welfare due to regulatory intervention. As can be seen, there are two areas in which the effect is positive because the welfare loss is smaller after intervention than before. These are the area where firms are pushed from price discrimination to unshrouded prices $(0.2<\alpha<0.33)$, and partially the area where firms are in an shrouded prices equilibrium before intervention and choose price discrimination thereafter $(0.8<\alpha<0.91){ }^{18}$ The welfare effect is zero in the area where firms unshroud the add-on price independent of whether the regulator intervenes or not $(\alpha<0.2)$. Otherwise, the welfare effect is negative $(0.33<\alpha<0.8$ and $\alpha>0.91)$. In the former case $(0.33<\alpha<0.8)$, firms adjust prices but the underlying equilibrium strategy - price discrimination - remains. In the latter case $(\alpha>0.91)$, firms are pushed from shrouded prices to price discrimination. Because a key element of shrouding and price discrimination is that all or a fraction of sophisticated consumers substitute away, the effect on welfare is negative as more consumers become sophisticated due to the regulatory intervention. In other words, regulation may well be successful on an individual level, as it induces some consumers to make individually better decisions - they no longer buy the expensive add-on. However, as long as firms' pricing strategies induce these consumers to substitute away and thus behave inefficiently, regulation may fail on a social level - economic welfare decreases.

In the example, consumer education can have a positive effect on welfare $(0.8<$ $\alpha<0.91)$ or a negative effect on welfare $(0.91<\alpha)$ if firms are pushed from shrouded prices to price discrimination. In the proof of Proposition 5 we show that the effect is negative whenever the error probability in classifying sophisticated consumers $1-\beta$

\footnotetext{
${ }^{18}$ Note that regulatory intervention also has a positive effect if it pushes firms directly from a shrouded prices equilibrium to an unshrouded prices equilibrium. This is the case either if a price discrimination equilibrium does not exist or if $\lambda_{R}$ is sufficiently large such that $\alpha^{\ddagger}<\frac{1}{1-\lambda_{R}} \alpha^{\dagger}$. This case is not reflected in the example.
} 
is relatively high and/or education makes relatively many consumers sophisticated, i.e., $\lambda_{R} \alpha$ is high. The reason is the following: If the educational boost is strong, firms adjust to this by switching from shrouded prices to price discrimination. Sophisticated consumers now buy the add-on if and only if firms offer it to them at a low price, otherwise they substitute away. If firms target sophisticated consumers inaccurately, substitution may actually increase and welfare declines. ${ }^{19}$

\subsection{Pitfalls for Regulatory Intervention}

The above results show that regulatory intervention has a negative effect on welfare if it increases the degree of consumer sophistication, but the increase is too small to change firms' equilibrium pricing strategies or relatively many consumers substitute away in a new price discrimination equilibrium. One possible course of action the regulator may consider is to boost the educational impact of his intervention on naive consumers, i.e., increase $\lambda_{R}$. While the chances of success of such an attempt seem rather bleak in the light of the available evidence (see, e.g., Choi et al., 2010), Figure 5 shows that an increase in $\lambda_{R}$ may, in fact, worsen the situation in terms of welfare until the boost is strong enough to push firms towards unshrouded prices.

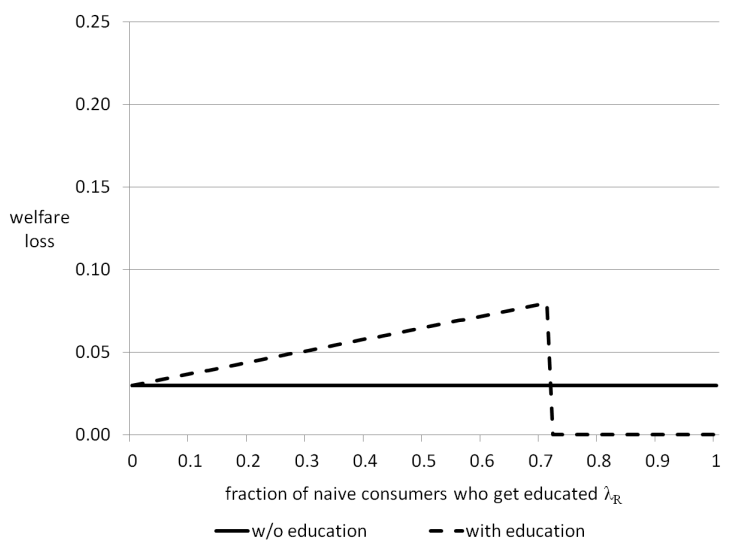

Note: Parameters are $\bar{p}=1, e=0.5, \beta=\gamma=0.8$ and a fraction of naive consumers before consumer education $\alpha=0.7$.

Figure 5: Welfare Effects of an Increase in the Educational Impact $\lambda_{R}$

\footnotetext{
${ }^{19}$ In our model, the error probability $1-\beta$ is exogenous and not affected by regulatory intervention. If $\beta$ is endogenous, it is intuitive that, if anything, regulatory intervention will increase the likelihood of misclassification because the composition of consumer groups has changed. This makes it even more likely that the welfare effect will be negative.
} 
In this example, parameters are chosen such that firms unshroud the add-on price if and only if $\alpha<0.2 .^{20}$ Starting with an ex-ante share of 70 percent naive consumers, regulatory intervention thus pushes firms from a price discrimination equilibrium to an unshrouded prices equilibrium if and only if $\lambda_{R}>5 / 7$. In this case, intervention has a positive effect on welfare as it reduces the welfare loss from 0.03 before the intervention to zero afterwards. For smaller values of $\lambda_{R}$, however, regulatory intervention increases the welfare loss up to 0.08 , i.e., more than double the welfare loss before regulation. This shows that a boost in the educational effect of the intervention may in principle be a good idea, but only if the boost is strong enough.

A second important pitfall is caused by the fact that welfare effects of consumer education critically depend on whether firms can price discriminate or not. If the regulator is unable to assess pricing strategies of firms correctly, the welfare effect of regulatory intervention may go either way.

Figure 6 illustrate this situation. In panel (a) and (b) of Figure 6, we consider a case in which firms' possibility to price discriminate makes consumer education favorable. Suppose the regulator observes that firms are in a shrouded prices equilibrium and correctly estimates the fraction of naive consumers to be $\alpha=0.5$. Further, suppose that educating consumers makes a fraction $\lambda_{R}=0.4$ of naive consumers informed. Then, panel (a) shows that the welfare effect of education is positive, i.e., the welfare loss decreases, if firms can use price discrimination. In contrast, the effect is negative, i.e. the welfare loss increases, if price discrimination is not possible, as panel (b) shows.

In panels (c) and (d) of Figure 6 the situation is the other way round. Now, price discrimination renders consumer education actually harmful. In this situation, suppose that the regulator again observes that firms are in a shrouded prices equilibrium. The fraction of ex-ante naive consumers is $\alpha=0.75$ and the educational effect $\lambda_{R}=0.75$. Then, as panel (c) shows, the welfare effect of consumer education is negative, i.e., the welfare loss increases, if firms can price discriminate. In contrast, the effect is positive and the welfare loss is actually reduced to zero, if price discrimination is not possible (panel $(\mathrm{d})$ ).

\footnotetext{
${ }^{20}$ Again, the parameters are the ones we have considered before (e.g., Figure 4 (b)).
} 


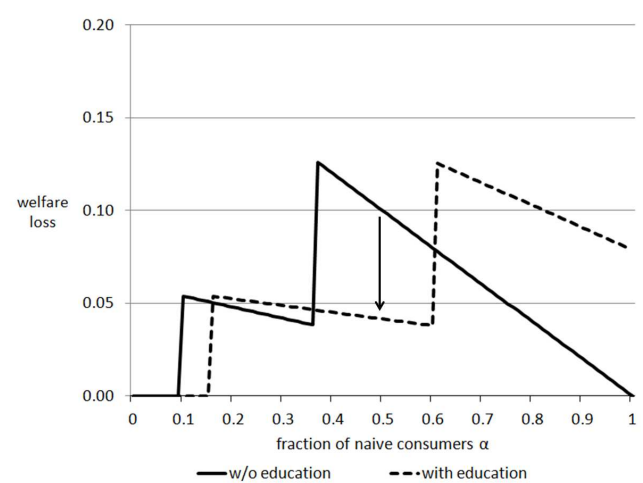

(a) Welfare Effects with PD

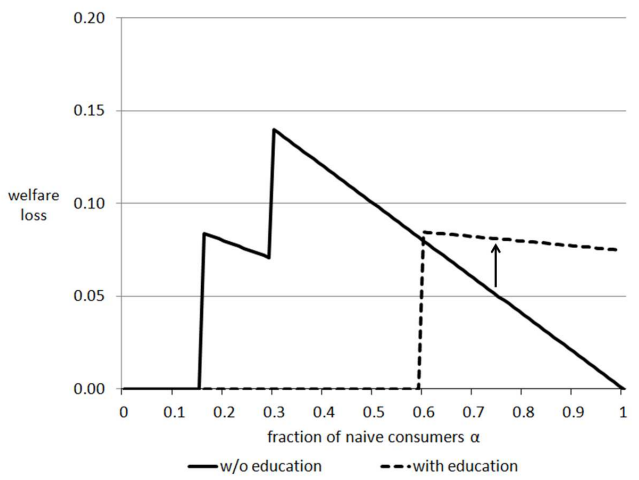

(c) Welfare Effects with PD

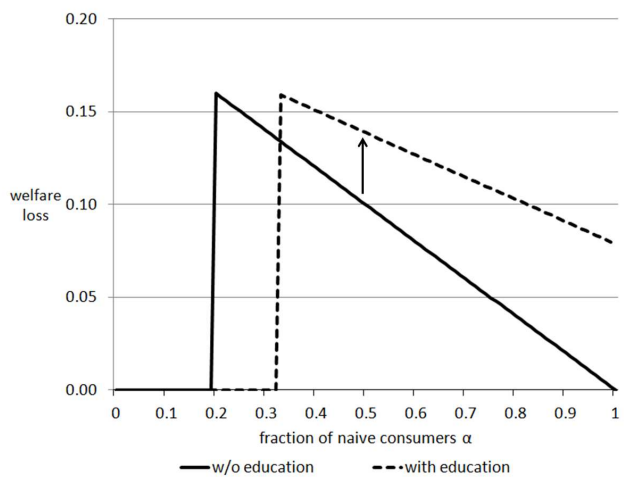

(b) Welfare Effects w/o PD

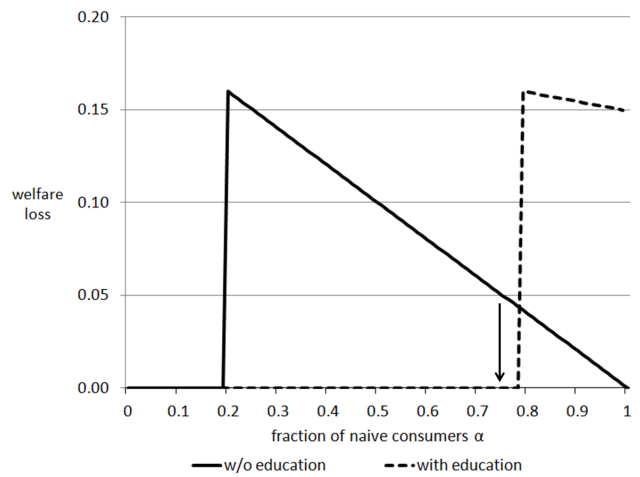

(d) Welfare Effects w/o PD

Note: Parameters in all panels are $\bar{p}=1, e=0.2$ and $\mu=0$. Firms' possibilities to price discriminate differ depending on $\beta$ and $\gamma$. These parameters are $\beta=0.7, \gamma=0.7$ for panel (a), $\beta \leq 1-\gamma$ for panel (b), $\beta=0.5, \gamma=0.7$ for panel (c), and $\beta \leq 1-\gamma$ for panel (d). The educational effect is $\lambda_{R}=0.4$ for panels (a) and (b), and $\lambda_{R}=0.75$ for panels $(c)$ and $(d)$. The arrows show a welfare loss or welfare gain from education for situations with an ex-ante fraction of naive consumers of $\alpha=0.5$ for panels (a) and (b) and $\alpha=0.75$ for panels (c) and (d).

Figure 6: Pitfalls for Regulatory Intervention

\section{Conclusion}

When firms exploit naive consumers, educating consumers looks like a good idea.

First, education should lead to better consumer decisions and hence lower consumer costs. Second, it should eventually cause firms under competitive pressure to disclose and to lower prices, thereby increasing welfare because sophisticated consumers no longer substitute away. Following this idea, policymakers who are concerned with excessive fees and financial damages of consumers in retail financial markets have started financial education initiatives all over the world during recent years.

Our analysis suggests that the effects of consumer education are actually more 
involved. If consumer education is sufficiently effective such that firms unshroud prices, all consumers indeed benefit and economic welfare increases. However, this may be unlikely to happen. Firms often use information to classify consumers, which allows them to price discriminate between naive and sophisticated consumers. Our results show that price discrimination is a symmetric equilibrium if firms can classify consumers relatively well and the fraction of naive consumers is neither very small nor very large. In consequence, a price equilibrium with fully unshrouded prices, which would socially be most efficient, is less likely to be achieved through consumer education. This even more so, as empirical studies suggest that consumer education often has only little impact on the behavior of naive consumers, presumably because the latter are unreceptive to the information or simply unwilling to be told how to decide.

If a boost from financial education does not lead to unshrouded prices for all consumers, educating consumers may in fact decrease economic welfare. Our results show that the welfare effects of education critically depend on the overall fraction of naive consumers, the success of consumer education, the reservation price for the add-on, substitution costs for sophisticated consumers, and the efficiency of price discrimination. Often, the regulator can only speculate about these things. Hence, the potential benefits of consumer eduction are accompanied by several significant fallacies.

As a general message our analysis suggests that regulators may not want to rely on consumer education to solve the problems of consumer protection and socially inefficient information and pricing strategies of firms. As our results show, consumer education is no panacea. 


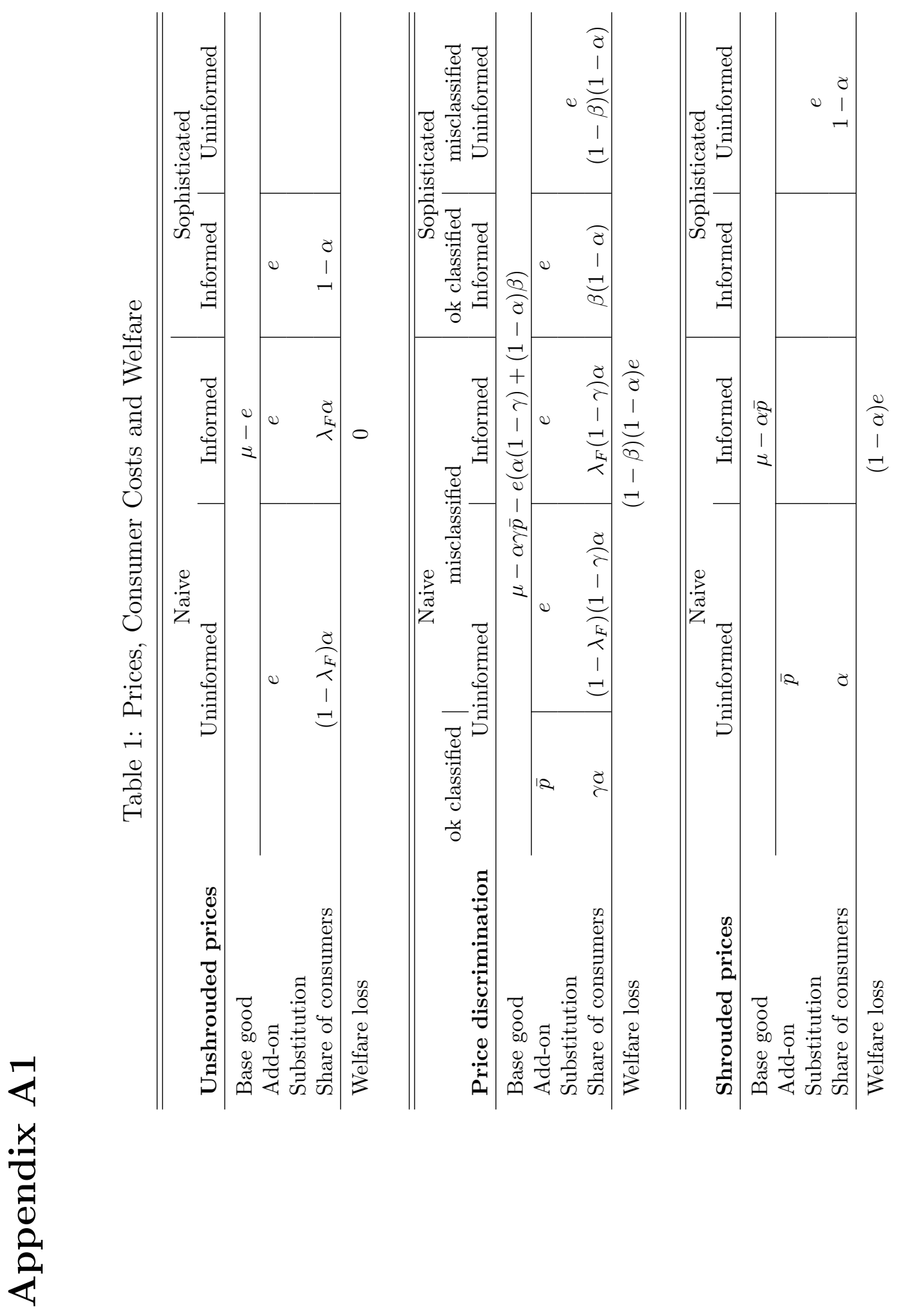




\section{Appendix A2: Proofs}

The proofs use various arguments and results from GL and Caplin and Nalebuff (1991). In particular, the existence of symmetric equilibrium is guaranteed by Caplin and Nalebuff (1991). Given the specification of demand $D\left(x_{i}\right)$, equilibrium prices are determined by the first-order condition $p+\hat{p}=\frac{D(0)}{D^{\prime}(0)}=: \mu$. The latter is equal to the average profit of a firm per consumer and represents a simple parametrization of the degree of competition in the industry.

\section{Proof of Proposition 1 (Price Equilibria):}

Note that if $\beta \leq 1-\gamma, \alpha^{\dagger}=\alpha^{\ddagger}=\frac{e}{\bar{p}}$. In this case, Proposition 1 is equivalent to Proposition 1 in GL (see also Corollary 1). Suppose therefore that $\beta>1-\gamma$, i.e., $\alpha^{\dagger}<\frac{e}{\bar{p}}<\alpha^{\ddagger}$.

Case 1: Suppose that $\alpha<\alpha^{\dagger}$. We show that unshrouding is an equilibrium. Suppose all firms except firm $i$ unshroud. If firm $i$ unshrouds as well, it optimally sets $\hat{p}=e$, yielding profit

$$
\begin{gathered}
(p+e)\left(1-\lambda_{F}\right) \alpha D\left(-p+p^{*}\right)+(p+e)\left(1-\left(1-\lambda_{F}\right) \alpha\right) D\left(-p-e+p^{*}+e\right) \\
=(p+e) D\left(-p+p^{*}\right) .
\end{gathered}
$$

The first term of (3) captures the profit firm $i$ makes from uninformed naive consumers, the second term captures the profit it makes from sophisticated and informed naive consumers. Solving the first-order condition yields a base good price $p=-e+\mu$.

Alternatively, firm $i$ can decide to shroud the add-on price or engage in price discrimination. GL show that shrouding is suboptimal if $\alpha<\frac{e}{\bar{p}}$, which holds in our case since $\alpha<\alpha^{\dagger} \leq \frac{e}{\bar{p}}$.

We now show that price discrimination does not exceed the profit from unshrouding, either. With price discrimination, firm $i$ optimally sets prices equal to the maximum willingness to pay of sophisticated and naive consumers, respectively, i.e., $\hat{p}_{S}=e$ and $\hat{p}_{N}=\bar{p}$. Because other firms unshroud, a fraction $\lambda_{F}$ of naive consumers become informed and behave just as sophisticated. Accordingly, price discrimination yields 
profit

$$
\begin{gathered}
(p+\bar{p})\left(1-\lambda_{F}\right) \alpha \gamma D\left(-p+p^{*}\right) \\
+p \lambda_{F} \alpha \gamma D\left(-p-e+p^{*}+e\right) \\
+(p+e)\left(1-\lambda_{F}\right) \alpha(1-\gamma) D\left(-p+p^{*}\right) \\
+(p+e) \lambda_{F} \alpha(1-\gamma) D\left(-p-e+p^{*}+e\right) \\
+(p+e)(1-\alpha) \beta D\left(-p-e+p^{*}+e\right) \\
+p(1-\alpha)(1-\beta) D\left(-p-e+p^{*}+e\right) \\
=\left(p+\bar{p}\left(1-\lambda_{F}\right) \alpha \gamma+e(\alpha(1-\gamma)+(1-\alpha) \beta)\right) D\left(-p+p^{*}\right) .
\end{gathered}
$$

The first and second term of (4) capture the profit firm $i$ makes from naive consumers who are classified correctly (which happens with ex-ante probability $\gamma$ ). On the one hand, this includes a fraction $1-\lambda_{F}$ of uninformed naive consumers who pay the high add-on price $\bar{p}$. On the other hand, this includes a fraction $\lambda_{F}$ of informed naive consumers who also get offered the high-priced add-on but substitute away. The third and fourth term represent the profit from misclassified naive consumers (which happens with ex-ante probability $1-\gamma$ ) that are offered the low add-on price and hence pay only $e$. On the one hand, this includes a fraction $1-\lambda_{F}$ of uninformed naive consumers; on the other hand, this includes a fraction $\lambda_{F}$ of informed naive consumers. The fifth term shows profits from sophisticated consumers who are classified correctly (which happens with ex-ante probability $\beta$ ) and pay $e$. Finally, the sixth term captures the profit from misclassified informed consumers who erroneously do not receive the low price offer, therefore rationally expect that $E \hat{p}=\bar{p}$ and hence substitute away.

Comparing (3) and (4) reveals that unshrouding yields strictly higher profit than price discrimination if and only if 


$$
\begin{aligned}
e & >\bar{p}\left(1-\lambda_{F}\right) \alpha \gamma+e(\alpha(1-\gamma)+(1-\alpha) \beta) \\
e & >\bar{p}\left(1-\lambda_{F}\right) \alpha \gamma+e \alpha(1-\gamma)+e \beta-e \alpha \beta \\
e(1-\beta) & >\alpha\left(\bar{p}\left(1-\lambda_{F}\right) \gamma+e(1-\gamma)-e \beta\right) \\
\frac{e(1-\beta)}{e(1-\beta)+\left(\bar{p}\left(1-\lambda_{F}\right)-e\right) \gamma} & >\alpha,
\end{aligned}
$$

which holds as $\alpha<\alpha^{\dagger}=\min \left(\frac{e}{\bar{p}}, \frac{e(1-\beta)}{e(1-\beta)+(\bar{p}-e) \gamma}\right)$. Thus, unshrouding is an equilibrium.

Case 2: Suppose that $\alpha>\alpha^{\ddagger}$. We show that an equilibrium exists, in which all firms shroud the add-on price. Suppose all firms except firm $i$ shroud. If firm $i$ shrouds as well, it optimally sets $\hat{p}=\bar{p}$, yielding profit

$$
\begin{gathered}
(p+\bar{p}) \alpha D\left(-p+p^{*}\right)+p(1-\alpha) D\left(-p-e+p^{*}+e\right) \\
=(p+\alpha \bar{p}) D\left(-p+p^{*}\right) .
\end{gathered}
$$

The first term of (5) captures the profit from naive consumers who buy the add-on at the high price $\bar{p}$. The second term captures the profit from sophisticated consumers who rationally expect the add-on to be priced at $E \hat{p}=\bar{p}$ and hence substitute away.

Again, we can use results from GL who show that unshrouding leads to lower profit if $\alpha>\frac{e}{\bar{p}}$, which holds in our case as $\alpha>\alpha^{\ddagger} \geq \frac{e}{\bar{p}}$. It thus again remains to be shown that price discrimination does not increase profit, either.

If all firms shroud, all naive consumers are uninformed unless they are misclassified by firm $i$ and erroneously get informed about the add-on. Hence, the profit from price discrimination is equal to: 


$$
\begin{gathered}
(p+\bar{p}) \alpha \gamma D\left(-p+p^{*}\right) \\
+(p+e) \alpha(1-\gamma)\left(1-\lambda_{F}\right) D\left(-p+p^{*}\right) \\
+(p+e) \alpha(1-\gamma) \lambda_{F} D\left(-p-e+p^{*}+e\right) \\
+(p+e)(1-\alpha) \beta D\left(-p-e+p^{*}+e\right) \\
+p(1-\alpha)(1-\beta) D\left(-p-e+p^{*}+e\right) \\
=(p+\alpha \gamma \bar{p}+e(\alpha(1-\gamma)+(1-\alpha) \beta)) D\left(-p+p^{*}\right) .
\end{gathered}
$$

The first term of (6) captures the profit firm $i$ makes from naive consumers who are classified correctly and hence pay the high add-on price $\bar{p}$. The second and third term capture the profit from naive consumers who are misclassified (which happens with ex-ante probability $1-\gamma)$. These consumers are offered the low add-on price and hence pay only $e$. A fraction $\left(1-\lambda_{F}\right)$ of these consumers stays uninformed while a fraction $\lambda_{F}$ becomes informed. The fourth term captures the profit from sophisticated consumers who are classified correctly (which happens with ex-ante probability $\beta$ ). The fifth term captures the profit from misclassified sophisticated consumers who erroneously do not receive the low price offer, therefore rationally expect that $E \hat{p}=\bar{p}$ and hence substitute away.

Comparing (5) and (6) reveals that shrouding yields strictly higher profit than price discrimination if and only if

$$
\begin{aligned}
\alpha \bar{p} & >\alpha \gamma \bar{p}+e(\alpha(1-\gamma)+(1-\alpha) \beta) \\
\alpha \bar{p} & >\alpha(e-e \gamma-e \beta+\bar{p} \gamma)+\beta e \\
\alpha(\bar{p}-e+e \gamma+e \beta-\bar{p} \gamma) & >\beta e \\
\alpha(e \beta+(\bar{p}-e)(1-\gamma)) & >\beta e \\
\alpha & >\frac{\beta e}{e \beta+(\bar{p}-e)(1-\gamma)} \\
\alpha & >\alpha^{\ddagger} .
\end{aligned}
$$

Thus, shrouding is an equilibrium. 
Case 3: Finally, suppose $\alpha^{\dagger}<\alpha<\alpha^{\ddagger}$. We show that price discrimination is an equilibrium. Suppose all other firms engage in price discrimination. If firm $i$ price discriminates, as well, it makes profit

$$
(p+\alpha \gamma \bar{p}+e(\alpha(1-\gamma)+(1-\alpha) \beta)) D\left(-p+p^{*}\right)
$$

equivalent to Equation (6). ${ }^{21}$

Alternatively, if firm $i$ shrouds, profit is equal to

$$
\begin{gathered}
(p+\bar{p}) \alpha \gamma D\left(-p+p^{*}\right) \\
+(p+\bar{p}) \alpha(1-\gamma)\left(1-\lambda_{F}\right) D\left(-p+p^{*}\right) \\
+p \alpha(1-\gamma) \lambda_{F} D\left(-p-e+p^{*}+e\right) \\
+p(1-\alpha) D\left(-p-e+p^{*}+e\right) \\
=\left(p+\bar{p} \alpha\left(\gamma+(1-\gamma)\left(1-\lambda_{F}\right)\right)\right) D\left(-p+p^{*}\right) .
\end{gathered}
$$

The first term of (8) captures the profit firm $i$ makes from uninformed naive consumers who are classified correctly (by all other firms who price discriminate) and hence pay the high add-on price $\bar{p}$. The second and third term capture the profit from naive consumers who are misclassified (by all other firms who price discriminate). A fraction $\left(1-\lambda_{F}\right)$ of these consumers stays uninformed and also pays the high add-on price $\bar{p}$ (second term). A fraction $\lambda_{F}$ becomes informed and substitutes away (third term). The fourth term captures the profit from sophisticated consumers who substitute away (or buy the low-priced add-on from a competitor).

Comparing (7) and (8) reveals that price discrimination yields strictly higher profit than shrouding if and only if

\footnotetext{
${ }^{21}$ We assume that all firms follow the same classification of consumers.
} 


$$
\begin{aligned}
\alpha \gamma \bar{p}+e(\alpha(1-\gamma)+(1-\alpha) \beta) & >\bar{p} \alpha\left(\gamma+(1-\gamma)\left(1-\lambda_{F}\right)\right) \\
\beta e+\alpha(\gamma \bar{p}+e-e \gamma-e \beta) & >\alpha\left(\bar{p} \gamma+\bar{p}(1-\gamma)\left(1-\lambda_{F}\right)\right) \\
\beta e & \left.>\alpha\left(\bar{p} \gamma+\bar{p}(1-\gamma)\left(1-\lambda_{F}\right)-e+e \gamma+e \beta-\bar{p} \gamma\right)\right) \\
\beta e & >\alpha\left(e \beta+\bar{p}(1-\gamma)\left(1-\lambda_{F}\right)-e(1-\gamma)\right) \\
\beta e & >\alpha\left(e \beta+\left(\bar{p}-\bar{p} \lambda_{F}-e\right)(1-\gamma)\right) \\
\frac{\beta e}{e \beta+\left(\bar{p}\left(1-\lambda_{F}\right)-e\right)(1-\gamma)} & >\alpha,
\end{aligned}
$$

which holds as $\alpha<\alpha^{\ddagger}=\max \left(\frac{e}{\bar{p}}, \frac{e \beta}{e \beta+(\bar{p}-e)(1-\gamma)}\right)$.

Furthermore, profit from unshrouding is equal to

$$
(p+e) D\left(-p+p^{*}\right)
$$

equivalent to Equation (3). Comparing (7) and (9) reveals that price discrimination yields strictly higher profit than unshrouding if and only if

$$
\begin{aligned}
\alpha \gamma \bar{p}+e(\alpha(1-\gamma)+(1-\alpha) \beta) & >e \\
\alpha(\gamma \bar{p}+e-e \gamma-e \beta) & >e-e \beta \\
\alpha & >\frac{e(1-\beta)}{e(1-\beta)+(\bar{p}-e) \gamma} \\
\alpha & >\alpha^{\dagger} .
\end{aligned}
$$

Thus, price discrimination is an equilibrium.

Q.E.D.

\section{Proof of Proposition 2 (Consumer Costs):}

Sophisticated consumers either buy the add-on at price $e$ or exert substitution costs of the same amount. Thus, total costs of consumption of sophisticated consumers depend on the price of the base good. Generally, if price discrimination is possible, i.e., $\alpha^{\dagger}<\frac{e}{\bar{p}}<\alpha^{\ddagger}$, the price of the base good equals

$$
\mu-\alpha \gamma \bar{p}-e(\alpha(1-\gamma)+(1-\alpha) \beta)
$$


for $\alpha^{\dagger}<\alpha<\alpha^{\ddagger}$. If price discrimination is not possible, an unshrouded prices equilibrium exists for $\alpha^{\dagger}<\alpha<\frac{e}{\bar{p}}$ with a base good price equal to $\mu-e$. Since $\alpha>\alpha^{\dagger}$, the former price is lower than the latter price. Similarly, for $\frac{e}{\bar{p}}<\alpha<\alpha^{\ddagger}$ a shrouded prices equilibrium exists if price discrimination is not possible. In this case, the base good price equals $\mu-\alpha \bar{p}$. Again, since $\alpha<\alpha^{\ddagger}$, the former price is lower than the latter price. This proves the first statement.

Next, consider prices of naive consumers. If price discrimination is not possible, naive consumers pay a total price of $\mu-e+e=\mu$ in an unshrouded prices equilibrium $\left(\alpha<\frac{e}{\bar{p}}\right)$ and a total price of $\mu-\alpha \bar{p}+\bar{p}=\mu+(1-\alpha) \bar{p}$ in a shrouded prices equilibrium $\left(\frac{e}{\bar{p}}<\alpha\right)$. If price discrimination is possible $\left(\alpha^{\dagger}<\alpha<\alpha^{\ddagger}\right)$, naive consumers who are correctly classified (with probability $\gamma$ ) buy the add-on at $p_{N}=\bar{p}$, and naive consumers who are misclassified (with probability $1-\gamma$ ) buy the add-on at $p_{S}=e$. The expected total price for naive consumers is equal to

$$
\begin{gathered}
\mu-\alpha \gamma \bar{p}-e(\alpha(1-\gamma)+(1-\alpha) \beta)+\gamma \bar{p}+(1-\gamma) e \\
=\mu+(1-\alpha)(\gamma \bar{p}+e(1-\gamma)-e \beta) .
\end{gathered}
$$

Since $e<\bar{p}$ and $\beta<1$, it immediately follows that this price is higher than $\mu$ (unshrouded prices equilibrium) but lower than $\mu+(1-\alpha) \bar{p}$ (shrouded prices equilibrium). This proves the second statement.

In a price discrimination equilibrium $\left(\alpha^{\dagger}<\alpha<\alpha^{\ddagger}\right)$, naive consumers who are misclassified pay a total price

$$
\mu-\alpha \gamma \bar{p}-e(\alpha(1-\gamma)+(1-\alpha) \beta)+e
$$

Since $\alpha^{\dagger}<\alpha$, this price is lower than $\mu$ (unshrouded prices equilibrium), and consequently also lower than $\mu+(1-\alpha) \bar{p}$ (shrouded prices equilibrium). This proves the third statement.

Finally, in a price discrimination equilibrium $\left(\alpha^{\dagger}<\alpha<\alpha^{\ddagger}\right)$, naive consumers that 
are correctly classified pay a total price

$$
\begin{aligned}
\mu & -\alpha \gamma \bar{p}-e(\alpha(1-\gamma)+(1-\alpha) \beta)+\bar{p} \\
& =\mu-\alpha \gamma \bar{p}-e \alpha(1-\gamma)-e(1-\alpha) \beta+\alpha \bar{p}+(1-\alpha) \bar{p} \\
& =\mu+\alpha(1-\gamma)(\bar{p}-e)+(1-\alpha)(\bar{p}-e \beta) .
\end{aligned}
$$

Since $e<\bar{p}$ and $\beta<1$, it immediately follows that this price is higher than $\mu$ (unshrouded prices equilibrium). Since $\alpha<\alpha^{\ddagger}$, this price is lower than $\mu+(1-\alpha) \bar{p}$ (shrouded prices equilibrium). This proves the last statement.

Q.E.D.

\section{Proof of Proposition 3 (Economic Welfare):}

Consider Table 1 in Appendix A1. In an unshrouded prices equilibrium, all consumers buy the add-on; hence the welfare loss is zero. In a price discrimination equilibrium, the fraction of sophisticated consumers who substitute away is equal to $(1-\beta)(1-\alpha)$. In a shrouded prices equilibrium, this fraction is equal to $1-\alpha$. Q.E.D.

\section{Proof of Lemma 1 (Price Equilibria with Consumer Education):}

Denote $\tilde{\alpha}:=\left(1-\lambda_{R}\right) \alpha$ the fraction of naive consumers after regulatory intervention. The result follows from Proposition 1 replacing $\alpha$ by $\tilde{\alpha}$.

Q.E.D.

\section{Proof of Proposition 4 (Effects of Consumer Education on Consumer}

\section{Costs):}

If an unshrouding equilibrium exists with and without intervention $\left(\alpha<\alpha^{\dagger}\right)$, all consumers face the same costs of consumption $\mu$. Thus, regulatory intervention has no effect. This proves the first statement.

In all other cases, expected consumer costs change through regulatory intervention. Consider first the sophisticated. Their costs of consumption solely depend on the price of the base good, which is $\mu-e$ in an unshrouded prices equilibrium, $\mu-\alpha \bar{p}$ in a shrouded prices equilibrium, and

$$
\mu-\alpha \gamma \bar{p}-e(\alpha(1-\gamma)+(1-\alpha) \beta)=\mu-\alpha(\gamma \bar{p}+e(1-\gamma)-e \beta)-e \beta
$$


in a price discrimination equilibrium (always before regulatory intervention). It can easily be seen that, if regulatory intervention lowers the fraction of naive consumers from $\alpha$ to $\left(1-\lambda_{R}\right) \alpha$, the price of the base good in a price discrimination or shrouded prices equilibrium increases. Further, if firms are pushed from a shrouded prices to a price discrimination equilibrium or from a price discrimination to an unshrouded prices equilibrium, the price of the base good increases as well, since $\mu-\alpha \bar{p}<$ $\mu-\alpha(\gamma \bar{p}+e(1-\gamma)-e \beta)-e \beta$ if $\alpha^{\ddagger}<\alpha<\alpha^{\sharp}$ and $\mu-\alpha(\gamma \bar{p}+e(1-\gamma)-e \beta)-e \beta<\mu-e$ if $\alpha^{\dagger}<\alpha<\alpha^{\S}$. Hence, consumer costs of sophisticated consumers always increase.

With regard to ex-ante naive consumers, consumer costs depend on whether a naive consumer becomes informed through education (with probability $\lambda_{R}$ ) or remains uninformed (with probability $1-\lambda_{R}$ ).

Consider first ex-ante naive consumers who remain uninformed. Just like the sophisticated, these consumers always pay a higher base good price. Since they remain naive, their costs on the add-on are unchanged except if firms are pushed from a shrouded prices to a price discrimination equilibrium. In this case, they are misclassified with positive probability which may lower their consumer costs. In particular, their costs decrease if $\alpha^{\ddagger}<\alpha<\alpha^{\sharp}$ and $\mu-\alpha \bar{p}+\bar{p}$ is larger than

$$
\begin{gathered}
\mu-\left(1-\lambda_{R}\right) \alpha \gamma \bar{p}-e\left(\left(1-\lambda_{R}\right) \alpha(1-\gamma)+\left(1-\left(1-\lambda_{R}\right) \alpha\right) \beta\right)+\gamma \bar{p}+(1-\gamma) e \\
=\mu+\left(1-\left(1-\lambda_{R}\right) \alpha\right)(\gamma \bar{p}+e(1-\gamma)-e \beta)
\end{gathered}
$$

which holds if $\lambda_{R}$ is sufficiently small (cf. equation 10 in the proof of Proposition 2).

Consider next the ex-ante naive consumers who become informed. These consumers pay a higher based good price just as all other consumers, but always save on the add-on. We consider all possible cases separately.

1) If firms are pushed from price discrimination to unshrouded prices $\left(\alpha^{\dagger}<\alpha<\right.$ $\alpha^{\S}$ ), consumer costs change from

$$
\begin{gathered}
\mu-\alpha \gamma \bar{p}-e(\alpha(1-\gamma)+(1-\alpha) \beta)+\gamma \bar{p}+(1-\gamma) e \\
=\mu+(1-\alpha)(\gamma \bar{p}+e(1-\gamma)-e \beta)
\end{gathered}
$$


to $\mu$, which constitutes a decline since $e<\bar{p}$.

2) If a price discrimination equilibrium exists with and without intervention $\left(\alpha^{\S}<\right.$ $\left.\alpha<\alpha^{\ddagger}\right)$, costs change from

$$
\mu-\alpha \gamma \bar{p}-e(\alpha(1-\gamma)+(1-\alpha) \beta)+\gamma \bar{p}+(1-\gamma) e
$$

to

$$
\mu-\left(1-\lambda_{R}\right) \alpha \gamma \bar{p}-e\left(\left(1-\lambda_{R}\right) \alpha(1-\gamma)+\left(1-\left(1-\lambda_{R}\right) \alpha\right) \beta\right)+e .
$$

Thus, regulatory intervention decreases consumer costs, if and only if

$$
\begin{aligned}
& \mu-\left(1-\lambda_{R}\right) \alpha \gamma \bar{p}-e\left(\left(1-\lambda_{R}\right) \alpha(1-\gamma)+\left(1-\left(1-\lambda_{R}\right) \alpha\right) \beta\right)+e \\
&<\mu-\alpha \gamma \bar{p}-e(\alpha(1-\gamma)+(1-\alpha) \beta)+\gamma \bar{p}+(1-\gamma) e \\
& \lambda_{R} \alpha \gamma \bar{p}+e \lambda_{R} \alpha(1-\gamma)-e \lambda_{R} \alpha \beta+e<\gamma \bar{p}+(1-\gamma) e \\
& \alpha \lambda_{R}(\gamma \bar{p}+e-\gamma e-e \beta)<(\bar{p}-e) \gamma \\
& \alpha<\frac{1}{\lambda_{R}} \frac{(\bar{p}-e) \gamma}{e(1-\beta)+(\bar{p}-e) \gamma} .
\end{aligned}
$$

Since the right hand side is larger than one (which can easily be derived from the fact that $\alpha^{\S}<1$ ), the condition is fulfilled for all $\alpha$.

3) If firms are pushed from shrouded prices to price discrimination $\left(\alpha^{\ddagger}<\alpha<\alpha^{\sharp}\right)$, costs change from $\mu+(1-\alpha) \bar{p}$ to

$$
\mu-\left(1-\lambda_{R}\right) \alpha \gamma \bar{p}-e\left(\left(1-\lambda_{R}\right) \alpha(1-\gamma)+\left(1-\left(1-\lambda_{R}\right) \alpha\right) \beta\right)+e .
$$

Thus, regulatory intervention decreases consumer costs, if and only if

$$
\begin{gathered}
\mu-\left(1-\lambda_{R}\right) \alpha \gamma \bar{p}-e\left(\left(1-\lambda_{R}\right) \alpha(1-\gamma)+\left(1-\left(1-\lambda_{R}\right) \alpha\right) \beta\right)+e<\mu+(1-\alpha) \bar{p} \\
-\left(1-\lambda_{R}\right) \alpha \gamma \bar{p}-e\left(1-\lambda_{R}\right) \alpha(1-\gamma)+e\left(1-\lambda_{R}\right) \alpha \beta+\alpha \bar{p}<\bar{p}+e \beta-e \\
\alpha<\frac{\bar{p}+e \beta-e}{\bar{p}+e \beta-\left(\gamma \bar{p}+(1-\gamma) e-\lambda_{R}(e(1-\beta)+(\bar{p}-e) \gamma)\right)} .
\end{gathered}
$$

By the same argument as before the right hand side is larger than one, so the condition 
is fulfilled for all $\alpha$.

4) Finally, if a shrouded prices equilibrium exists with and without regulatory intervention $\left(\alpha^{\sharp}<\alpha\right)$, costs change from $\mu+(1-\alpha) \bar{p}$ to $\mu-\left(1-\lambda_{R}\right) \alpha \bar{p}+e$. Thus, regulatory intervention decreases costs, if and only if

$$
\begin{aligned}
\mu-\left(1-\lambda_{R}\right) \alpha \bar{p}+e & <\mu+(1-\alpha) \bar{p} \\
-\alpha \bar{p}+\lambda_{R} \alpha \bar{p}+e & <\bar{p}-\alpha \bar{p} \\
\alpha & <\frac{1}{\lambda_{R}}\left(1-\frac{e}{\bar{p}}\right) .
\end{aligned}
$$

Again, the right hand side is larger than one, because $\alpha^{\sharp}<1$. Thus, costs decrease. Q.E.D.

\section{Proof of Proposition 5 (Welfare Effects of Consumer Education):}

Consider Table 1 in Appendix A1. If an unshrouded prices equilibrium exists with and without regulatory intervention $\left(\alpha<\alpha^{\dagger}\right)$, the welfare loss is always zero. This proves the first statement.

If firms are pushed from price discrimination to an unshrouded prices equilibrium $\left(\alpha^{\dagger}<\alpha<\alpha^{\S}\right)$, the welfare loss falls from $(1-\beta)(1-\alpha) e$ to zero. This proves the second statement.

The third statement summarizes the results for the remaining cases. If firms are pushed from shrouded prices to price discrimination $\left(\alpha^{\ddagger}<\alpha<\alpha^{\sharp}\right)$, the welfare loss changes from $(1-\alpha) e$ to $(1-\beta)\left(1-\left(1-\lambda_{R}\right) \alpha\right) e$. Accordingly, the net effect of regulatory intervention is positive if and only if

$$
\begin{aligned}
(1-\alpha) e & >(1-\beta)\left(1-\left(1-\lambda_{R}\right) \alpha\right) e \\
(1-\alpha) e & >\left(1-\left(1-\lambda_{R}\right) \alpha\right) e-\beta\left(1-\left(1-\lambda_{R}\right) \alpha\right) e \\
0 & >\lambda_{R} \alpha e-\beta\left(1-\left(1-\lambda_{R}\right) \alpha\right) e \\
\beta\left(1-\left(1-\lambda_{R}\right) \alpha\right) e & >\lambda_{R} \alpha e \\
\beta & >\frac{\lambda_{R} \alpha}{1-\left(1-\lambda_{R}\right) \alpha} .
\end{aligned}
$$

Depending on $\beta, \lambda_{R}$ and $\alpha$, this condition may or may not hold. This proves the 
fourth statement.

Finally, if a shrouded prices equilibrium exists without and with regulatory intervention $\left(\alpha^{\sharp}<\alpha\right)$, the welfare loss is $(1-\alpha) e$ and $\left(1-\left(1-\lambda_{R}\right) \alpha\right) e$, respectively. Thus, welfare decreases by $\lambda_{R} \alpha e$ through regulatory intervention. Similarly, if a price discrimination equilibrium exists without and with regulatory intervention $\left(\alpha^{\S}<\alpha<\alpha^{\ddagger}\right)$, the welfare loss is equal to $(1-\beta)(1-\alpha) e$ and $(1-\beta)\left(1-\left(1-\lambda_{R}\right) \alpha\right) e$, respectively. Thus, welfare decreases by $(1-\beta) \lambda_{R} \alpha e$ in this case. This proves the last statement.

Q.E.D. 


\section{References}

Agarwal, S., Amromin, G., Ben-David, I., Chomsisengphet, S., Evanoff, D. D., 2009. Do financial counseling mandates improve mortgage choice and performance? Evidence from a legislative experiment, Federal Reserve Bank of Chicago Working Paper 2009-07.

Anderson, S. P., de Palma, A., Thisse, J.-F., 1992. Discrete Choice Theory of Product Differentiation. Cambridge, MA: MIT Press.

Armstrong, M., Vickers, J., 2012. Consumer protection and contingent charges. Journal of Economic Literature 50 (2), 477-493.

Bernanke, B. S., 2013. Financial and economic education. Speech at the 13th Annual RISE Forum, Dayton, Ohio, April 4, 2013.

Beshears, J., Choi, J. J., Laibson, D., Madrian, B. C., 2011. How does simplified disclosure affect individuals' mutual fund choices? In: Wise, D. A. (Ed.), Explorations in the Economics of Aging. Chicago: University of Chicago Press, pp. 75-96.

Bhattacharya, U., Hackethal, A., Kaesler, S., Loos, B., Meyer, S., 2012. Is unbiased financial advice to retail investors sufficient? Answers from a large field study. Review of Financial Studies 25 (4), 975-1032.

Caplin, A., Nalebuff, B., 1991. Aggregation and imperfect competition: On the existence of equilibrium. Econometrica 59 (1), 25-59.

Carlin, B. I., 2009. Strategic price complexity in retail financial markets. Journal of Financial Economics 91 (3), $278-287$.

Carlin, B. I., Manso, G., 2011. Obfuscation, learning, and the evolution of investor sophistication. Review of Financial Studies 24 (3), 754-785.

Choi, J., Laibson, D., Madrian, B. C., 2010. Why does the law of one price fail? An experiment on index mutual funds. Review of Financial Studies 23 (4), 1405-1432. 
De Meza, D., Irlenbusch, B., Reyniers, D., 2008. Financial Capability: A Behavioural Economics Perspective, Consumer Research 69, Financial Services Authority, UK.

De Meza, D., Reyniers, D., 2012. Every shroud has a silver lining: The visible benefits of hidden surcharges. Economics Letters 116 (2), 151-153.

Ellison, G., 2006. Bounded rationality in industrial organization. In: Advances in Economics and Econometrics: Theory and Applications, Ninth World Congress. Vol. 2. Cambridge, UK: Cambridge University Press, pp. 142-74.

Gabaix, X., Laibson, D., 2006. Shrouded attributes, consumer myopia, and information suppression in competitive markets. Quarterly Journal of Economics 121 (2), $505-540$.

Glaeser, E. L., Ujhelyi, G., 2010. Regulating misinformation. Journal of Public Economics $94(3-4), 247-257$.

Grubb, M., 2012. Consumer inattention and bill-shock regulation. Unpublished working paper.

Hall, R. E., 1997. The inkjet aftermarket: An economic analysis. Unpublished working paper.

Hastings, J. S., Madrian, B. C., Skimmyhorn, W. L., 2013. Financial literacy, financial education, and economic outcomes. Annual Review of Economics 5, 347-373, also available as NBER Working Paper No. 18412.

Heidhues, P., Köszegi, B., Murooka, T., 2012. The market for deceptive products. Unpuplished working paper.

Henderson, B. J., Pearson, N. D., 2011. The dark side of financial innovation: A case study of the pricing of a retail financial product. Journal of Financial Economics $100(2), 227-247$.

Ko, K. J., Williams, J., 2013. The effects of regulating hidden add-on costs. Unpublished working paper. 
Lacko, J. M., Pappalardo, J. K., 2010. The failure and promise of mandated consumer mortgage disclosures: Evidence from qualitative interviews and a controlled experiment with mortgage borrowers. American Economic Review 100 (2), 516-21.

Lal, R., Matutes, C., 1994. Retail Pricing and Advertising Strategies. Journal of Business 67, 345-370.

Miao, C., 2010. Consumer myopia, standardization and aftermarket monopolization. European Economic Review 54 (7), 931-946.

OECD, 2009. Financial literacy and consumer protection: Overlooked aspects of the crisis, OECD Recommendation.

Spiegler, R., 2011. Bounded rationality and industrial organization. New York, NY: Oxford University Press. 


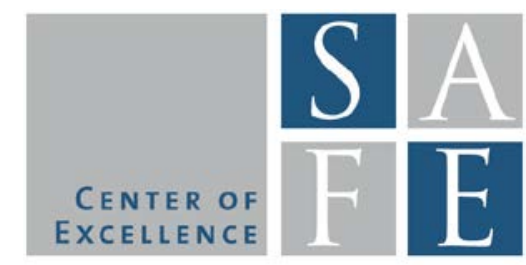

WORKING PAPER SERIES

\section{Recent Issues}

No. 46 Marcel Bluhm, Ester Faia, Jan Pieter Krahnen

No. 45 Fabio Castiglionesi, Fabio Ferozzi, Gyongyi Loranth, Loriana Pelizzon

No. 44 Lorenz S. Schendel

No. 43 Lorenz S. Schendel

No. 42 Reint Gropp, John Krainer, Elizabeth Laderman

No. 41 Adrian Buss, Raman Uppal, Grigory Vilkov

No. 40 Holger Kraft, Lorenz S. Schendel, Mogens Steffensen

No. 39 H. Evren Damar, Reint Gropp, Adi Mordel

No. 38 Claudia Lambert, Felix Noth, Ulrich Schüwer

No. 37 Deyan Radev

No. 36 Florian Hett, Alexander Schmidt
Monetary Policy Implementation in an Interbank Network: Effects on Systemic Risk

Liquidity Coinsurance and Bank Capital

Critical Illness Insurance in Life Cycle Portfolio Problems

Consumption-Investment Problems with Stochastic Mortality Risk

Did Consumers Want Less Debt? Consumer Credit Demand versus Supply in the Wake of the 2008-2009 Financial Crisis

Asset Prices in General Equilibrium with Recursive Utility and Illiquidity Induced by Transaction Costs

Life Insurance Demand under Health Shock Risk

Banks' financial distress, lending supply and consumption expenditure

How do insured deposits affect bank risk? Evidence from the 2008 Emergency Economic Stabilization Act

Systemic Risk and Sovereign Debt in the Euro Area

Bank Rescues and Bailout Expectations: The Erosion of Market Discipline During the Financial Crisis 